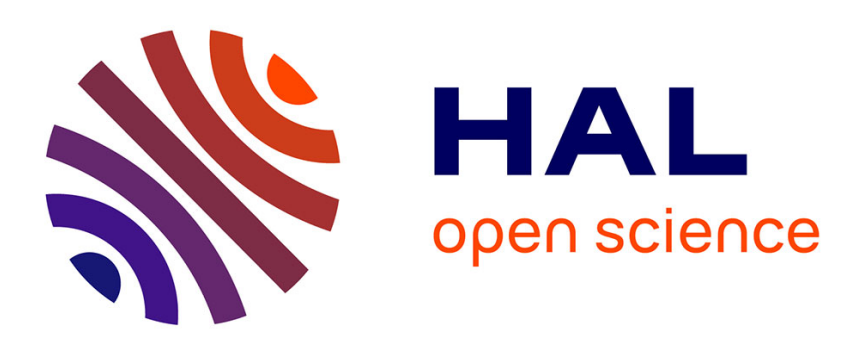

\title{
Physical, chemical, and optical properties of regional hazes dominated by smoke in Brazil
}

Jeffrey Reid, Peter Hobbs, Ronald Ferek, Donald Blake, J. Vanderlei Martins, Michael Dunlap, Catherine Liousse

\section{- To cite this version:}

Jeffrey Reid, Peter Hobbs, Ronald Ferek, Donald Blake, J. Vanderlei Martins, et al.. Physical, chemical, and optical properties of regional hazes dominated by smoke in Brazil. Journal of Geophysical Research: Atmospheres, 1998, 103 (D24), pp.32059-32080. 10.1029/98JD00458 . hal-03119689

\section{HAL Id: hal-03119689 \\ https://hal.science/hal-03119689}

Submitted on 25 Jan 2021

HAL is a multi-disciplinary open access archive for the deposit and dissemination of scientific research documents, whether they are published or not. The documents may come from teaching and research institutions in France or abroad, or from public or private research centers.
L'archive ouverte pluridisciplinaire HAL, est destinée au dépôt et à la diffusion de documents scientifiques de niveau recherche, publiés ou non, émanant des établissements d'enseignement et de recherche français ou étrangers, des laboratoires publics ou privés. 


\section{UC Irvine}

\section{UC Irvine Previously Published Works}

\section{Title}

Physical, chemical, and optical properties of regional hazes dominated by smoke in Brazil

\section{Permalink}

https://escholarship.org/uc/item/4hz6q116

\section{Journal}

Journal of Geophysical Research Atmospheres, 103(D24)

\section{ISSN}

0148-0227

\section{Authors}

Reid, JS

Hobbs, PV

Ferek, RJ

et al.

\section{Publication Date}

1998

\section{DOI}

10.1029/98JD00458

License

https://creativecommons.org/licenses/by/4.0/4.0

Peer reviewed 


\title{
Physical, chemical, and optical properties of regional hazes dominated by smoke in Brazil
}

\author{
Jeffrey S. Reid, ${ }^{1,2}$ Peter V. Hobbs, ${ }^{1}$ Ronald J. Ferek, ${ }^{1,3}$ Donald R. Blake, ${ }^{4}$ \\ J. Vanderlei Martins, ${ }^{5}$ Michael R. Dunlap, ${ }^{6}$ and Catherine Liousse ${ }^{7}$
}

\begin{abstract}
Gas and particle measurements are described for optically thick regional hazes, dominated by aged smoke from biomass burning, in the cerrado and rain forested regions of Brazil. The hazes tended to be evenly mixed from the surface to the trade wind inversion at $3-4 \mathrm{~km}$ in altitude. The properties of aged gases and particles in the regional hazes were significantly different from those of young smoke ( $<4$ min old). As the smoke aged, the total amount of carbon in non-methane hydrocarbon species $(\mathrm{C}<11)$ was depleted by about one third due to transformations into $\mathrm{CO}_{2}, \mathrm{CO}$, and reactive molecules, and removed by dry deposition and/or by conversion to particulate matter. As the smoke particles aged, their sizes increased significantly due to coagulation and mass growth by secondary species (e.g., ammonium, organic acids and sulfate). During aging, condensation and gas-to-particle conversion of inorganic and organic vapors increased the aerosol mass by $\sim 20-40 \%$. One third to one half of this mass growth likely occurred in the first few hours of aging due to the condensation of large organic molecules. The remaining mass growth was probably associated with photochemical and cloud-processing mechanisms operating over several days. Changes in particle sizes and compositions during aging had a large impact on the optical properties of the aerosol. Over a 2 to 4 day period, the fine particle mass-scattering efficiency and single-scattering albedo increased by $1 \mathrm{~m}^{2} \mathrm{~g}^{-1}$, and $\sim 0.06$, respectively. Conversely, the Angstrom coefficient, backscatter ratio, and mass absorption efficiency decreased significantly with age.
\end{abstract}

\section{Introduction}

Biomass burning, which produces an estimated $104 \mathrm{Tg} \mathrm{yr}^{-1}$ of particles worldwide [Andreae, 1991], is the second largest source of anthropogenic aerosol particles [Intergovernmental Panel on Climate Change (IPCC), 1995]. Particles from biomass buming not only have significant local and regional effects but also may affect global atmospheric chemistry and the Earth's climate.

South America accounts for $30 \%$ of all tropical biomass buming. Artaxo et al. [1994] showed that during the dry season, biomass burning produces major perturbations in atmospheric fine particle concentration at ground level in the Amazon Basin and cerrado regions of Brazil. Optical depths due to smoke in this region are frequently in excess of 1 and have been measured as high as 3 [Ross et al., this issue]. For such high optical depths, instantaneous net radiative forcing

\footnotetext{
${ }^{1}$ Department of Atmospheric Sciences, University of Washington,
Seattle.

${ }^{2}$ Now at SPAWARSYSCEN SAN DIEGO 0883, 49170 Propagation Path, San Diego, Califomia 92152-7385.

${ }^{3}$ Also at Office of Naval Research, Arlington, Virginia.

${ }^{4}$ Department of Chemistry, University of Califomia, Irvine.

${ }^{5}$ Instituto de Física, Universidade de São Paulo, São Paulo, Brazil.

${ }^{6}$ Facility for Advanced Instrumentation, University of California, Davis.

${ }^{7}$ Centre des Faibles Radioactivités, Laboratoire Mixte CNRS-CEA, Gif-Sur-Yvette, France.
}

Copyright 1998 by the American Geophysical Union.

Paper number 98JD00458.

0148-0227/98/98JD-00458\$09.00 due to aerosol from biomass burning can be as high as -36 $\mathrm{W} \mathrm{m}^{-2}$ [Christopher et al., 1996].

To model the direct radiative forcing of aerosols, measurements of three basic optical properties are required: mass-scattering efficiency, backscatter ratio, and single-scattering albedo. In a companion paper, we have provided these measurements for young ( $<4$ min old) smoke from biomass burning in Brazil [Reid and Hobbs, this issue]. However, since aerosols from biomass burning undergo rapid evolution [Westphal and Toon, 1991; Hobbs et al., 1997], measurements on young smoke should not be assumed to be applicable to smoke that dominates regional hazes or affects even larger areas. Therefore parameters applicable to aged smoke should be used in regional and global climate models. In this paper we describe and discuss such measurements, obtained aboard the University of Washington (UW) Convair C-131A research aircraft in the Smoke, Clouds, and Radiation-Brazil (SCAR-B) field project [Hobbs, 1996; Kaufman et al., this issue]. The measurements comprise the physical, chemical, and optical properties of the regional palls of smoke that cover millions of square kilometers of the cerrado and (Amazon) forested regions of Brazil during the dry season.

Many physical and chemical processes can influence gases and particles in smoke as they evolve from their sources in Brazil (Figure 1). After being emitted, the smoke particles disperse rapidly into the atmosphere, but they are usually capped by the strong trade wind inversion at a height of about 3 to $4 \mathrm{~km}$. Smoke from hundreds of fires mix with biogenic emissions from forests, suspended soil particles, and anthropogenic pollutants. The most vigorous fires often have a capping cumulus cloud above them, which can process the 


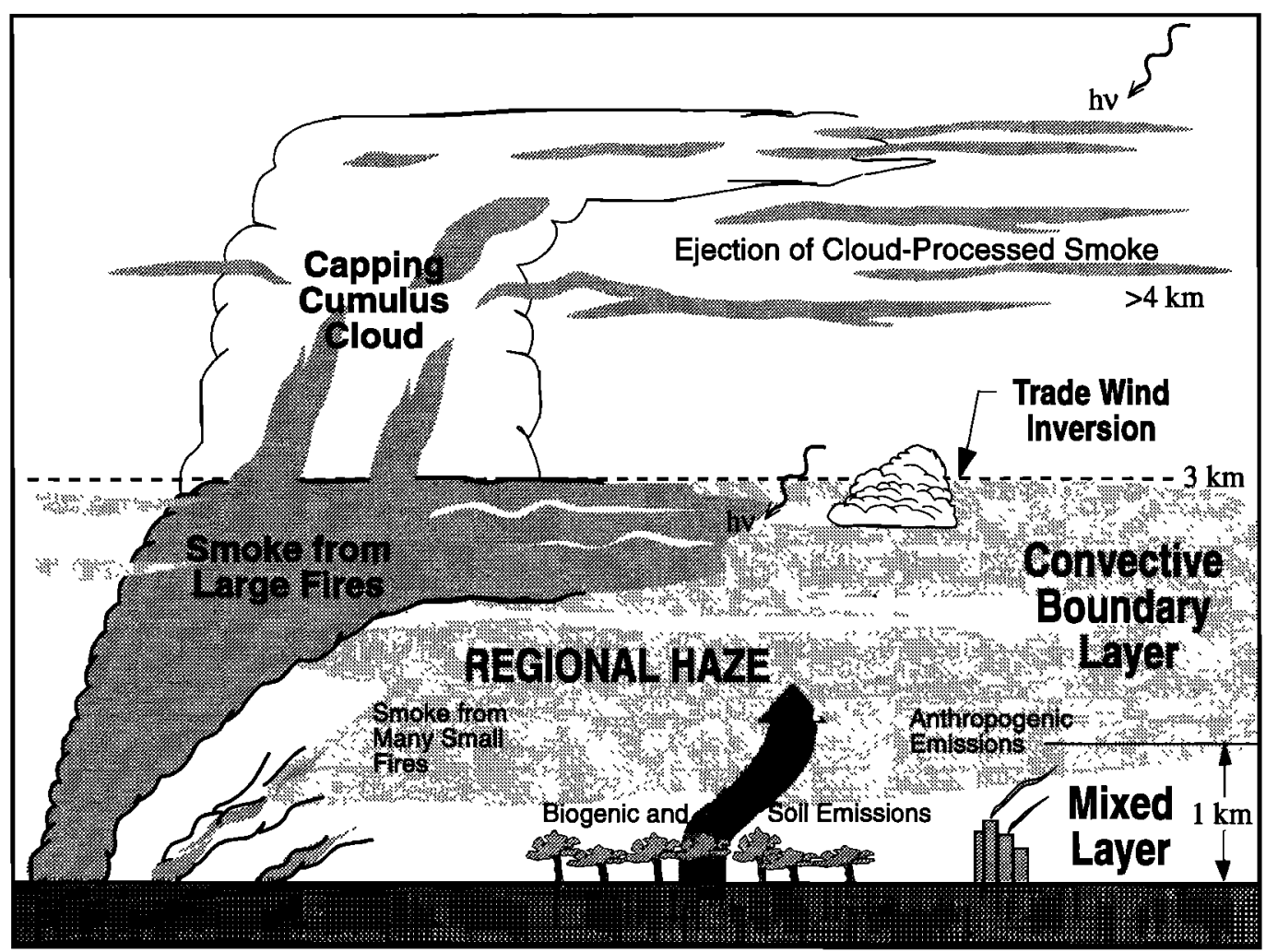

Figure 1. Schematic depicting some of the processes involved in the evolution of smoke particles from biomass burning as they spread from their sources to regional and continental scales in Prazil.

smoke before ejecting it aloft. In some cases, clouds break through the trade wind inversion and eject the smoke as layers into the more stable free troposphere, where it can be transported over large distances [Pickering et al., 1996]. As the smoke disperses, it undergoes photochemical transformations, gas-to-particle conversion, and particle coagulation. Furthermore, smoke can be entrained into clouds in the boundary layer, thereby increasing the rates of some chemical reactions. These various processes result in a thick photochemical "soup" up to the height of the trade wind inversion that can have physical and chemical properties quite different from those of young smoke.

Smoke emissions in Brazil have a strong diumal cycle. Fires are generally ignited in the late morning through late afternoon [Prins et al., 1997]. Thus hazes sampled in the early to midmorning are likely to contain aged smoke from the previous day.

\section{Experimental Design and Instrumentation}

\subsection{Design and Methods}

In SCAR-B the UW C-131A aircraft was used to study a wide variety of regional hazes dominated by smoke. Flight operations were conducted from four bases: Brasília (the capitol of Brazil, $14^{\circ} \mathrm{S}, 48^{\circ} \mathrm{W}$ ), Cuiabá (in the state of Mato Grosso, $16^{\circ} \mathrm{S}, 56^{\circ} \mathrm{W}$ ), Porto Velho (Rondonia, $9^{\circ} \mathrm{S}, 64^{\circ} \mathrm{W}$ ), and Marabá(Pará $5^{\circ} \mathrm{S}, 49^{\circ} \mathrm{W}$ ). A map showing the locations of these sites is presented by Kaufman et al. [this issue]. Brasilia and Cuiabá are in the cerrado region, while Porto Velho and Marabá are in the western and eastern portions of the Amazon
Basin, respectively. Since the aerosols around Brasilia had a strong local urban component, they are not discussed here.

The data collected can be divided into three broad categories. Roughly half of the data were collected during nine vertical profiles in which measurements were made from near the surface up through the trade wind inversion. Results of column closure tests for these flights are described by Ross et al. [this issue]. Comprehensive measurements on regional hazes were also obtained immediately prior to obtaining emission factor measurements [Ferek et al., this issue]. Finally, data were collected on the transit flights between the four bases of operation.

A description of the instrumentation aboard the UW C-131A aircraft, the flight plans, and mission summaries are given by Hobbs [1996]. However, a brief description of the methods and measurements relevant to this paper are given here.

The UW C-131A carries aboard instrumentation for both continuous and parcel sampling. Measurements of basic state parameters, particle size distributions, light scattering, and absorption coefficients were made continuously. "Grab" samples for particle analysis were collected in a $2.5 \mathrm{~m}^{3}$ Velostat bag, which is filled by ram air in 10-14 s. To minimize wall losses in the bag, air samples did not exceed $0.75 \mathrm{~m}^{3}$ per bag. The particle cut point of the inlet and bag system is $\sim 4 \mu \mathrm{m}\left(\mathrm{PM}_{4}\right)$. Samples from the grab bag were passed through filters (for subsequent total mass concentration measurements and chemical composition analysis). Particle size distribution and aerosol humidification factor measurements [Kotchenruther and Hobbs, this issue] were also made on grab bag samples. 
Correlation coefficients between measurements made with the continuously recording instruments (e.g., nephelometers) and measurements made via the grab bag were derived by averaging the continuous measurements over the period during which the grab bag was filled. Since the regional hazes were generally very uniform, the timing of the grab samples and the continuous measurements was not critical.

\subsection{Gas Measurements}

Ozone concentrations were measured continuously using a Monitor Labs 8410 ethylene chemiluminescence analyzer. Twenty-seven gas samples were collected in 2-L stainless steel canisters. The canisters were filled with air samples to approximately 28 psi by a metal bellows pump. The canisters were sent to the University of California, Irvine, where they were analyzed by gas chromatography using a flame ionization detector (FID). The sample size for each analysis was $303 \mathrm{~cm}^{3}$. Concentrations of $\mathrm{CO}_{2}, \mathrm{CO}, \mathrm{CH}_{4}$, and 21 hydrocarbons $(C<11)$ were measured for each sample. Measurement precision for the alkanes, alkenes, and alkynes was $2 \%$ or 8 parts per trillion volume (pptv), whichever was larger. The total carbon concentration in nonmethane hydrocarbons (NMHCs) was determined by integrating the area of all peaks between the $\mathrm{C}-2$ and the $\mathrm{C}-11$ region and dividing this area by the methane response factor.

The concentrations of five halocarbons were determined from the canister samples using an electron capture detector. These were $\mathrm{CH}_{3} \mathrm{Cl}, \mathrm{CHCl}_{3}, \mathrm{CH}_{3} \mathrm{I}, \mathrm{CH}_{3} \mathrm{Br}$, and $\mathrm{CHBr}_{3}$, which were measured with precisions of $1.2,12,12,8$, and $12 \%$, respectively.

\subsection{Aerosol Composition}

In SCAR-B, sixty-two $37 \mathrm{~mm}$ Teflon filters were exposed in regional hazes in Brazil from the C-131A aircraft. Twenty-five additional field blanks (for quality control) were used. Filters were gravimetrically analyzed in a humidity controlled chamber $(\mathrm{RH}=35 \%)$ to determine the ambient aerosol dry mass concentration $\left(c_{m}\right.$, in $\mu \mathrm{g} \mathrm{m}^{-3}$ ). From the control and field blanks we estimated that the uncertainty in the measured filter masses were less than $\pm 6 \mu \mathrm{g}$. For comparison, the mean filter loading for the regional smoke samples was $45 \mu \mathrm{g}$. Most filters exposed to regional haze were filled with more than one bag; the average filtered volume was $0.85 \mathrm{~m}^{3}$. Following gravimetric measurements of the filters for determining total aerosol mass, the Teflon filters were subjected to water extraction and then ion exchange chromatography (IC). This analysis yielded the concentrations of the following ions: $\mathrm{Ca}^{2+}, \mathrm{Cl}^{-}, \mathrm{K}^{+}, \mathrm{Mg}^{2+}$, $\mathrm{Na}^{+}, \mathrm{NH}_{4}^{+}, \mathrm{NO}_{2}^{-}, \mathrm{NO}_{3}^{-}, \mathrm{SO}_{4}^{-}$, and $\mathrm{C}_{2} \mathrm{O}_{4}^{-}$(oxalate). $\mathrm{Na}^{+}, \mathrm{K}^{+}, \mathrm{NH}_{4}^{+}$, $\mathrm{SO}_{4}^{-}$, and $\mathrm{C}_{2} \mathrm{O}_{4}^{=}$were measured to have a $\pm 3 \%$ uncertainty or better and were always more than two standard deviations $(2 \sigma)$ above the detectable limits. All other species were measured to have a $\pm 15 \%$ uncertainty or better.

Forty-one polycarbonate filter samples were collected simultaneously with the Teflon filters. The polycarbonate filters were gravimetrically analyzed and then subjected to proton induced $X$ ray emission (PIXE) spectroscopy to determine the concentration of up to 20 elements. In this paper we discuss PIXE data for $\mathrm{K}, \mathrm{S}$, and Fe. Filter mass, $\mathrm{Ca}^{2+}$, $K$, and $S$ were used to check the consistency of the data between the IC and the PIXE analysis. Iron was used as the primary indicator of the fraction of soil in the aerosol.
Regressions between aerosol concentrations derived from the Teflon and the polycarbonate filters yielded a 1:1 slope and a correlation greater than $80 \%$. Comparisons of elements from the IC and PIXE showed that $80 \%$ of the sulfur in the aerosol was soluble and/or easily oxidized to sulfate, and $80 \%$ and $50 \%$ of the $\mathrm{K}$ and $\mathrm{Ca}$ were soluble.

Particulate carbon concentrations in the aerosol were determined by thermal analysis [Cachier et al., 1989] of 38 quartz filters. The filters were subjected $\mathrm{HCl}$ vapors for 24 hours to remove any carbonates. The black carbon (BC) content of the aerosol was determined through coulometric titration after the sample was thermally pretreated for 2 hours at $340^{\circ} \mathrm{C}$ in pure oxygen. A discussion of the quality of the BC data is given by Reid et al. [this issue]. As recommended by Reid et al., all of the BC concentrations were increased by $25 \%$ to account for measurement bias in the $\mathrm{BC}$ thermal analysis.

Twenty additional polycarbonate filters were taken and subjected to scanning electron microscopy (SEM) and energy dispersive $\mathrm{X}$ ray analysis (EDX). The purpose of this analysis was to determine the properties of coarse particles in the regional hazes dominated by smoke. The SEM used was an ISI DS 130 operating at $20 \mathrm{keV}$ with a current of approximately $100 \mathrm{nA}$; EDX was performed with an Oxford Instruments EDS detector with a $\mathrm{Be}$ window. Over 300 coarse particles were micrographed; of these, 50 were subjected to EDX to determine qualitative elemental composition (the derived elements were similar to those of PIXE).

Species concentrations from IC and PIXE, as well as the aerosol specific absorption, were subjected to principal component analysis (PCA) and absolute principal component analysis (APCA) [Thurston and Spengler, 1985; Hopke, 1985; Artaxo et al., 1994]. Results from these analyses were used to separate out orthogonal factors (or components) and their apportionments in the atmosphere. The PCA analysis was used to determine qualitative relationships between the orthogonal factors of the aerosol and the input parameters.

\subsection{Particle Size Distributions}

Aboard the UW C-131A aircraft were two instruments for measuring particle size spectra that were used in this study: a differential mobility particle sizer (DMPS) and the PMS passive cavity aerosol spectrometer probe (PCASP). The DMPS measures aerosol size spectrums from 0.01 to $0.6 \mu \mathrm{m}$ diameter based on particle electromobility [Winklmayr et al., 1991]. Since this instrument requires a $4 \mathrm{~min}$ analysis time, samples were drawn from the grab bag. The PCASP-100X is a wing-mounted, optical particle counter that measures dried aerosol from 0.1 to $3 \mu \mathrm{m}$ in diameter. Particle sizes are derived from measurements of the light that scatters from angles between $35^{\circ}$ and $135^{\circ}$. The instrument was calibrated using polystyrene latex spheres of known sizes. Sizing errors can develop for particles that have indices of refraction which differ from those of latex (1.59-0i). To compensate for this, the PCASP response curve was adjusted [Pueschel et al., 1990] for particles with indices of refraction of 1.5-0.02i (from closure calculations by Reid and Hobbs [this issue]).

Both the DMPS and the PCASP number distributions were parameterized by a lognormal curve fit:

$$
d N=\frac{1}{\sqrt{2 \pi} \ln \sigma_{g c}} \exp \left[-\frac{\left(\ln d_{p}-\ln C M D\right)^{2}}{2\left(\ln \sigma_{g c}\right)^{2}}\right] d\left(\ln d_{p}\right)
$$


where $d_{p}$ is the particle diameter, $C M D$ is the count median diameter, and $\sigma_{g c}$ is the geometric standard deviation. A similar expression was used to parameterize the particle volume distributions.

\subsection{Light Scattering}

Light-scattering measurements were made with a three-wavelength $(\lambda=450,550,700 \mathrm{~nm})$ nephelometer custom built for the UW by MS Electron Incorporated [Hegg et al., 1996; Anderson et al., 1996]. Aerosols were sampled continuously through a pressure-regulated, isokinetic inlet and dried to a relative humidity $<35 \%$. The nephelometer had a backscatter shutter to determine total hemispheric backscattering (between $90^{\circ}$ and $170^{\circ}$ ). For particles less than $0.6 \mu \mathrm{m}$ diameter, such as those encountered in this study, the truncation errors were small and accounted for in part. We estimate that this produced a $3 \%$ uncertainty in our scattering measurements. To mitigate the errors produced by a non-Lambertian light source, which most nephelometers suffer from, the lamp in our nephelometer was fitted with a special ground glass window.

\subsection{Light Absorption}

For a complete description and error analysis of the measurements of aerosol absorption and single-scattering albedo aboard the C-131A in SCAR-B the reader is referred to Reid et al. [this issue]. The shortwave light absorption coefficient $\left(\sigma_{a}\right)$ of the aerosol was measured using the integrating plate (IP) and optical reflectance (OR) techniques on the Teflon and polycarbonate filter samples, respectively. These measurements were made at a wavelength of $550 \mathrm{~nm}$ and broadband visible for the IP and OR methods, respectively. Continuous absorption measurements were made using a particle soot/absorption photometer (PSAP), manufactured by Radiance Research. The PSAP operated at a wavelength of 550 $\mathrm{nm}$ and used a quartz filter substrate. The integration time for each data point was $1 \mathrm{~min}$.
Overall, these various methods produced $\sigma_{a}$ values within $\pm 20 \%$ of each other. Errors in the derived single-scattering albedos of individual samples were within \pm 0.05 . Results from the IP method are used principally in this paper.

\section{Meteorological and Haze Characteristics}

Airborne measurements were obtained in the vicinity of Cuiabá, Porto Velho, and Marabá from August 23 to September 18, 1995. A summary of the aerosol and major gas species concentrations by region is given in Table 1 . Also included in Table 1 is the carbon apportionment of the NMHC. All of the measurements were made in fairly uniform regional hazes. To illustrate some typical atmospheric structures and smoke distributions encountered during SCAR-B, meteorological and aerosol data from seven vertical profiles are listed in Table 2.

In the remainder of this section we describe the general meteorological conditions and haze characteristics during the period that we obtained measurements at each of the three base sites. GOES 8 satellite images for the time periods discussed may be found in the work of Kaufman et al. [this issue].

\subsection{Cuiabá}

Flight operations with the UW C-131A were conducted around Cuiabá from August 24 to September 1. From August 24 to 28 there was a weak $\left(<5 \mathrm{~m} \mathrm{~s}^{-1}\right.$ ) easterly flow. What appeared to be mainly locally generated smoke was uniformly distributed in a layer that extended from the surface to a strong trade wind (subsidence) inversion at $2500 \mathrm{~m}(740 \mathrm{hPa})$. The midday atmospheric lapse rate was dry adiabatic, and the equivalent potential temperature was nearly constant with height, which indicate strong vertical mixing. The skies were mostly cloud free, with the exception of some thin cirrus and scattered cumulus humilis ( $<300 \mathrm{~m}$ thick) at the tops of the strongest thermals. Capping cumulus clouds on large fires were observed to emit thin smoke layers at an altitude of about $1 \mathrm{~km}$ above the trade wind inversion.

Table 1. Concentrations of Particles $\left(\mathrm{PM}_{4}\right)$ and Gases (Mean \pm Standard Deviation) and Nonmethane Hydrocarbon (NMHC) Budget Observed in Regional Hazes Dominated by Smoke From Biomass Burning Over Cuiabá, Porto Velho, and Marabá During SCAR-B

\begin{tabular}{|c|c|c|c|c|}
\hline & $\begin{array}{l}\text { Cuiabá } \\
\text { (Local) }\end{array}$ & $\begin{array}{l}\text { Cuiabá } \\
\text { (Aged) }\end{array}$ & Porto Velho & Marabá \\
\hline \multicolumn{5}{|c|}{ Concentrations of Particles and Gases } \\
\hline $\begin{array}{l}\text { Particle concentration, } \mu \mathrm{g} \mathrm{m}^{-3} \\
\mathrm{O}_{3}, \text { ppbv } \\
\mathrm{CO}_{2}, \mathrm{Ppmv} \\
\mathrm{CO} \text {, ppbv } \\
\mathrm{NMHCs} \text {, ppbc } \\
\mathrm{CH}_{4}, \text { ppmv }\end{array}$ & $\begin{array}{c}66 \pm 33 \\
95 \pm 15 \\
359 \pm 3 \\
440 \pm 165 \\
29 \pm 15 \\
1.76 \pm 0.03\end{array}$ & $\begin{array}{c}110 \pm 60 \\
102 \pm 30 \\
362 \pm 0.6 \\
763 \pm 119 \\
58 \pm 10 \\
1.79 \pm 0.01\end{array}$ & $\begin{array}{c}68 \pm 42 \\
70 \pm 15 \\
359 \pm 2 \\
566 \pm 155 \\
41 \pm 10 \\
1.78 \pm 11.4\end{array}$ & $\begin{array}{c}50 \pm 32 \\
61 \pm 10 \\
358 \pm 2.3 \\
482 \pm 245 \\
29 \pm 16 \\
1.78 \pm 0.03\end{array}$ \\
\hline \multicolumn{5}{|c|}{ NMHCs Carbon Budget (by Percent Carbon) } \\
\hline Ethane & $7.6 \pm 1.4$ & $10.4 \pm 3.0$ & $9.2 \pm 3.0$ & $11.2 \pm 2.5$ \\
\hline Ethene & $9.6 \pm 3.9$ & $6.4 \pm 1.10$ & $5.1 \pm 4.1$ & $9.8 \pm 6.1$ \\
\hline Ethyne & $5.8 \pm 1.3$ & $5.8 \pm 1.75$ & $5.1 \pm 2.0$ & $5.6 \pm 1.1$ \\
\hline Propane & $1.8 \pm 0.6$ & $2.7 \pm 0.8$ & $2.3 \pm 1.0$ & $2.6 \pm 0.3$ \\
\hline Propene & $4.0 \pm 3.1$ & $1.0 \pm 0.4$ & $1.3 \pm 1.2$ & $3.2 \pm 2.4$ \\
\hline Benzene & $9.5 \pm 1.5$ & $8.3 \pm 0.4$ & $8.2 \pm 3.8$ & $11.0 \pm 4.9$ \\
\hline Toluene & $4.1 \pm 1.5$ & $3.3 \pm 0.5$ & $3.0 \pm 2.6$ & $8.1 \pm 2.3$ \\
\hline Others & $4.3 \pm 2.6$ & $2.1 \pm 0.4$ & $2.8 \pm 1.5$ & $4.8 \pm 2.6$ \\
\hline Total identified carbon, \% & $46.7 \pm 6.3$ & $40.0 \pm 3.8$ & $37.0 \pm 7.4$ & $56.3 \pm 9.3$ \\
\hline
\end{tabular}


Table 2. Meteorological and Other General Characteristics for Seven Vertical Profiles Made by the UW C-131A Aircraft in Regional Hazes in Brazil

\begin{tabular}{|c|c|c|c|c|c|c|c|}
\hline Parameter & Cuiabá & Cuiabá & $\begin{array}{l}\text { Cuiabá } \\
\text { (Aged) }\end{array}$ & $\begin{array}{l}\text { Cuiabá } \\
\text { (Aged) }\end{array}$ & Porto Velho & Porto Velho & Marab \\
\hline $\begin{array}{l}\text { UW flight number } \\
1995 \\
\text { UTC } \\
\text { NASA photometer site } \\
\text { Cloud type } \\
\text { Cloud coverage, \% } \\
\text { Optical depth } \\
\text { at } \lambda=550 \mathrm{~nm}\end{array}$ & $\begin{array}{c}1692 \\
\text { Aug. } 23 \\
1630 \\
\text { Cuiabá } \\
\text { clear } \\
\text { clear } \\
\sim 0.1\end{array}$ & $\begin{array}{c}1694 \\
\text { Aug. } 24 \\
1945 \\
\text { INPE } \\
\text { Ci } \\
\text { thin } \\
0.8\end{array}$ & $\begin{array}{c}1696 \\
\text { Aug. } 30 \\
1500 \\
\text { Pantanal } \\
\text { Ac } \\
30-50 \\
1.7\end{array}$ & $\begin{array}{c}1697 \\
\text { Sept. } 1 \\
1300 \\
\text { Pantanal } \\
\text { Ac } \\
70-100 \\
1.5\end{array}$ & $\begin{array}{c}1700 \\
\text { Sept. } 5 \\
1945 \\
\text { Jamari } \\
\mathrm{Cu} \\
25 \\
2.3\end{array}$ & $\begin{array}{c}1703 \\
\text { Sept. } 5 \\
1700 \\
\text { Jamari } \\
\mathrm{Cu} \\
30 \\
1.4\end{array}$ & $\begin{array}{c}1712 \\
\text { Sept. } 17 \\
1500 \\
\text { none } \\
\mathrm{Cu} \\
60 \\
-0.3\end{array}$ \\
\hline \multicolumn{8}{|c|}{ Mixed Layer } \\
\hline $\begin{array}{l}\text { Inversion height, } \mathrm{km} \\
\text { Inversion pressure, } \mathrm{hPa} \\
\text { Inversion temp., }{ }^{\circ \mathrm{C}} \\
\text { Inversion dew point, }{ }^{\circ} \mathrm{C} \\
\text { Aerosol concentration, } \\
\mu \mathrm{g} \mathrm{m}^{-3} \text { at STP }\end{array}$ & $\begin{array}{l}\text { at PBL } \\
\text { at PBL } \\
\text { at PBL } \\
\text { at PBL } \\
\text { at PBL }\end{array}$ & $\begin{array}{l}\text { at PBL } \\
\text { at PBL } \\
\text { at PBL } \\
\text { at PBL } \\
\text { at PBL }\end{array}$ & $\begin{array}{c}0.57 \\
944 \\
28 \\
10 \\
110\end{array}$ & $\begin{array}{c}0.43 \\
960 \\
29 \\
9 \\
200\end{array}$ & $\begin{array}{c}0.9 \\
911 \\
26 \\
18 \\
180\end{array}$ & $\begin{array}{c}2.5 \\
740 \\
11 \\
6 \\
75\end{array}$ & $\begin{array}{l}\text { at } P B L \\
\text { at PBL } \\
\text { at PBL } \\
\text { at PBL } \\
\text { at PBL }\end{array}$ \\
\hline & & & $P B L / C B L$ & & & & \\
\hline $\begin{array}{l}\text { Inversion height, } \mathrm{km} \\
\text { Inversion pressure, } \mathrm{hPa} \text { ) } \\
\text { Inversion temp., }{ }^{\circ} \mathrm{C} \\
\text { Inversion dew point, }{ }^{\circ} \mathrm{C} \\
\text { Aerosol concentration, } \\
\mu \mathrm{g} \mathrm{m}^{-3} \text { at STP }\end{array}$ & $\begin{array}{c}2.3 \\
757 \\
10 \\
-1 \\
30\end{array}$ & $\begin{array}{c}2.7 \\
718 \\
8 \\
-1 \\
75\end{array}$ & $\begin{array}{c}3.5 \\
650 \\
0 \\
-3 \\
100\end{array}$ & $\begin{array}{l}3.9 \\
622 \\
-2 \\
-4 \\
85\end{array}$ & $\begin{array}{l}3.8 \\
629 \\
3.5 \\
-10 \\
140\end{array}$ & $\begin{array}{c}4.1 \\
-600 \\
1 \\
-3 \\
80\end{array}$ & $\begin{array}{c}2.1 \\
770 \\
12 \\
11 \\
40\end{array}$ \\
\hline
\end{tabular}

"At PBL" means the mixed layer extended to the top of the planetary boundary layer (or trade wind inversion). $\mathrm{CBL}$, convective boundary layer.

The hazes over Cuiabá during this time period were most strongly affected by locally and perhaps regionally generated smoke. The mixed layer had the lowest smoke concentrations $\left(10-60 \mu \mathrm{g} \mathrm{m}^{-3}\right)$ observed in this study. CO concentrations in the planetary boundary layer (PBL) varied widely between 200 and 600 parts per billion volume (ppbv). Ozone levels in Cuiabá during this period were high, averaging $70 \mathrm{ppbv}$ in the late morning to over $110 \mathrm{ppbv}$ in the late aftemoon.

Forty-one percent of the carbon in NMHC were speciated, with the majority of the carbon apportioned to hydrocarbons with 2 or 3 carbon atoms $(30 \%)$ and aromatics $(13 \%)$. This is significantly lower than the roughly $80 \%$ of the carbon speciated in NMHC reported by Ferek et al. [this issue] for young smoke ( $<4 \mathrm{~min}$ old) from individual fires in Brazil. This decrease is probably a result of intense photochemistry, as suggested by the high ozone levels. The unspeciated $53 \%$ of carbon in NMHC is likely to be a suite of hydrocarbons with complicated structures such as organic acid vapors, oxygenated aromatics, and aldyhydes [Larson and Koenig, 1994].

Using the $\mathrm{CO}_{2}$ and $\mathrm{CO}$ data from the gas canisters, the average modified combustion efficiency $\left(\mathrm{MCE} \equiv\left[\mathrm{CO}_{2}\right] /[\mathrm{CO}]\right.$ $\left.+\left[\mathrm{CO}_{2}\right]\right)$ of the smoke in Cuiabá was 0.94 . This suggests that over $85 \%$ of the smoke was from flaming combustion [Ward, 1990]. This is reasonable, since most of the fires around Cuiabá are of cerrado and grass lands, which consist of predominantly small and dry fuel.

During UW flights 1696 and 1697 (on August 30 and September 1) over the Pantanal southeast of Cuiabá, aged smoke in high concentrations from the Amazon Basin was advected from the north. The age of this smoke is somewhat uncertain but was most likely from 2 to 4 days old. During this period the atmosphere was decoupled into a mixed layer that extended from the surface to $500 \mathrm{~m}(952 \mathrm{hPa})$ and a convective boundary layer (CBL) or residual layer (the previous day's $\mathrm{CBL}$ ) that extended to approximately $3700 \mathrm{~m}$ $(625 \mathrm{hPa})$. The mixed layer was neutrally stratified and capped by a strong $\left(2^{\circ} \mathrm{C}\right)$ inversion that was $200 \mathrm{~m}$ thick. Fine-mode particle concentrations in the mixed layer were $>120 \mu \mathrm{g} \mathrm{m}^{-3}$, resulting in roughly $30 \%$ of the total aerosol optical depth being in the lowest $500 \mathrm{~m}$ [Ross et al., this issue]. The smoke in the mixed layer was probably primarily derived from local fires.

The residual layer had a stable lapse rate $\left(10^{\circ} \mathrm{C} \mathrm{km}^{-1}\right)$, and the equivalent potential temperature decreased slowly with height $\left(1.8^{\circ} \mathrm{C} \mathrm{km}^{-1}\right)$, making the layer slightly conditionally unstable. A thin altocumulus layer $(<100 \mathrm{~m}$ thick with coverage ranging from 30 to $100 \%$ ) was present at the top of the residual layer. Liquid water contents in the clouds ranged from 0.03 to $0.13 \mathrm{~g} \mathrm{~m}^{-3}$. Smoke in the $\mathrm{CBL} /$ residual layer was well mixed, with fairly uniform particle concentrations averaging $80 \mu \mathrm{g} \mathrm{m}^{-3}$ and $\mathrm{CO}$ concentrations varying from 700 to $900 \mathrm{ppbv}$. The average MCE of the smoke varied between 0.89 and 0.92 , indicating that $\sim 60 \%$ of the smoke was due to flaming combustion. The relatively large smoldering contribution to this smoke confirms that the source of most of the smoke was forest fires to the north. Ozone concentrations remained high and showed the same temporal pattern as for the period dominated by locally generated smoke.

\subsection{Porto Velho}

Flights were made in Porto Velho from September 5 to 13 (UW flights 1700-1707). Porto Velho was selected to obtain measurements of smoke generated by burning in the Amazon 
Basin. Winds were easterly at $5-10 \mathrm{~m} \mathrm{~s}^{-1}$, and the haze included smoke particles generated from thousands of fires over $-3000 \mathrm{~km}$ of fetch. Consequently, the regional haze around Porto Velho can be a mixture of fresh ( $<2$ hours) and well-aged smoke ( $>3$ days old). By analyzing the trajectories of large smoke plumes and convective complexes seen on daily GOES 8 images, we found that during the period in which our flights occurred, the smoke over Porto Velho was at most 3 to 4 days old.

During the period of our measurements, Porto Velho was on the edge of the intertropical convergence zone (ITCZ), which produced much moister conditions than were encountered in Cuiabá. Cumulus mediocris and cumulus congestus were present, with sky coverage of $30-60 \%$, and cloud liquid water contents ranged from $0.4-2.5 \mathrm{~g} \mathrm{~m}^{-3}$. Cloud bases were from 700 to $1000 \mathrm{~m}$, and cloud tops usually reached no more than $4000 \mathrm{~m}$. However, by midday, isolated cumulonimbus clouds often developed with some cloud tops higher than $10 \mathrm{~km}$.

By midday, a weakly defined mixed layer was usually visible which extended from the surface to $1-2 \mathrm{~km}$. However, smoke was usually well mixed from the surface to a weak trade wind inversion at $3-4 \mathrm{~km}$, with particle mass concentrations ranging from 30 to $190 \mu \mathrm{g} \mathrm{m}^{-3}$. The optical depth of the PBL was typically above 1 but sometimes as large as 3 . CO concentrations in the convective boundary layer were typically between 300 and $1000 \mathrm{ppbv}$, although values as high as $1400 \mathrm{ppbv}$ were measured. The MCE of the smoke over Porto Velho ranged from 0.65 to 0.97 , with a mean of 0.89 . This implies that on average, the smoke was equally partitioned between flaming and smoldering combustion.

Measured ozone concentrations in Porto Velho were significantly lower than in Cuiabá, averaging 70 ppbv. However, the mean carbon apportionment for smoke in Porto Velho was similar to that of aged smoke in Cuiabá. Because there was much variability in the age and history of the smoke encountered, the carbon apportionment varied widely.

\subsection{Marabá}

Flights with the C-131A were carried out in Marabá on September 16 and 17 (UW flights 1710-1713). Marabá was selected to measure relatively young smoke from forest and slash burning. With a prevailing easterly flow of $10 \mathrm{~m} \mathrm{~s}^{-1}$ at $850 \mathrm{hPa}$, air trajectories were over the continent for only 24-30 hours before reaching Marabá. Previous observations from AVHRR satellite data of biomass buming upwind of Maraba showed few fires within $200-300 \mathrm{~km}$ of the coast [Pereira et al., 1996]. Thus smoke in the Marabá region was probably no more than 18-24 hours old.

While the C-131A aircraft was in Marabá, the ITCZ moved south; consequently, there was a further increase in convective activity. By midday, cumulus mediocris and cumulus congestus clouds covered more than $50 \%$ of the sky, scattered cumulonimbus were present, the mixed layer extended to $2 \mathrm{~km}$, and no trade wind inversion was detectable.

Hazes over Marabá were dominated by fairly young smoke that was significantly influenced by cloud processing. Smoke was frequently seen exiting from cumulus congestus and cumulonimbus clouds. Fine particle concentrations in Marabá ranged from 30 to $105 \mu \mathrm{g} \mathrm{m}^{-3}$. Small forest and grass fires were prevalent, even in the morning hours. Two flights were made on both of the days in Maraba, one in the morning and one in the aftemoon. A distinct diumal cycle was apparent in smoke concentrations and properties. At $1000 \mathrm{LT}, \mathrm{CO}$ concentrations in the PBL were under $400 \mathrm{ppbv}$. Even this early in the day, there was sufficient convective activity to keep the atmosphere relatively well mixed. Few local smoke sources were visible, so the smoke studied in the mornings was likely advected from fires on the previous day located up to $500 \mathrm{~km}$ away. The average value of the MCE of the smoke was 0.87 . This suggests that the regional haze was enriched with smoke from smoldering combustion throughout the night. In the afternoon, many local fires were visible and smoke concentrations increased by more than a factor of 2 . The mean MCE of the haze also increased to 0.90 in the afternoon.

Because the smoke in Marabá was relatively young and was located beneath considerable cloud cover, the amount of gas oxidation through photochemistry was probably minimal. Ozone levels averaged $60 \mathrm{ppbv}$ from midday to late afternoon. The reduced potential for photochemical reactions also manifested itself in an increase (to $56 \%$ ) in the number of identifiable hydrocarbons in Maraba, compared to an average of $39 \%$ in the other two locations.

\section{Evolution of the Gaseous Emissions}

Ferek et al. [this issue] show that $\mathrm{CO}$ is highly correlated with all of the major hydrocarbons emitted by biomass burning in Brazil. They also found good correlations between $\mathrm{CO}$ and the methyl halide species: methyl chloride $\left(\mathrm{CH}_{3} \mathrm{Cl}\right)$, chloroform $\left(\mathrm{CHCl}_{3}\right)$, methyl bromide $\left(\mathrm{CH}_{3} \mathrm{Br}\right)$, and methyl iodide $\left(\mathrm{CH}_{3} \mathrm{I}\right)$. These correlations hold for all fires, regardless of fuel type or combustion efficiency. This correlation is particularly useful since $\mathrm{CO}$ is a relatively long-lived species and is produced by combustion. Thus by comparing the ratios of a hydrocarbon species to $\mathrm{CO}$ in regional hazes and young smoke, the average enrichment/depletion rates for various species during smoke evolution can be derived.

Table 3 lists these ratios for all of the hydrocarbon and halocarbon species that we measured in SCAR-B in regional hazes dominated by smoke, as well as for young smoke. The ratios were defined by the regression line of each species to $\mathrm{CO}$. These regressions were performed using all of the canister samples for regional haze dominated by smoke, regardless of location. Fifteen of the 27 canisters were collected in Porto Velho; thus Porto Velho is heavily weighted in the regressions.

Methane is a very stable hydrocarbon in the troposphere. Therefore it should not be transformed significantly by aging over several days. As expected, there is no statistically significant difference in the ratio of methane to $\mathrm{CO}$ between young and aged smoke (Table 3). This is a good indicator that the regional hazes we studied were not significantly affected by urban anthropogenic sources.

Table 3 shows that as the smoke evolved from individual fires into a regional haze, there were significant transformations and depletions of many hydrocarbon species. Most dramatic is the removal of one third of all of the carbon in NMHC species. This is shown by the regression relation between the total carbon in NMHC to CO for young and aged smoke (Figure 2). If these species remained in the vapor phase in any molecule with carbon numbers less than 11 , they would probably have been detected by the gas chromatograph. Therefore they were transformed by photochemical reactions 
Table 3. Regression Slopes for Various Chemical Species Versus CO for Young Smoke, All of the Regional Hazes Sampled in SCAR-B, and for Brasílian Hazes in TRACE A as Reported by Blake et al. [1996]

\begin{tabular}{|c|c|c|c|c|c|c|c|}
\hline \multirow[b]{2}{*}{ Species } & \multicolumn{5}{|c|}{ SCAR-B } & \multicolumn{2}{|l|}{ TRACE A } \\
\hline & $\begin{array}{l}\text { Young Smoke, } \\
\text { pptv ppbv } \text { pl- }^{-1}\end{array}$ & $r^{2}$ & $\begin{array}{l}\text { Regional Haze, } \\
\text { pptv ppbv }{ }^{-1}\end{array}$ & $\begin{array}{c}\text { Background } \\
\text { Concentration, pptv }\end{array}$ & $r^{2}$ & $\begin{array}{l}\text { Regional Haze, } \\
\text { pptv ppbv }\end{array}$ & $r^{2}$ \\
\hline $\begin{array}{l}\mathrm{CH}_{4} \\
\mathrm{C} \text { in } \mathrm{NMHC} \\
(\mathrm{C}<11)\end{array}$ & $\begin{array}{l}98 \pm 10 \\
95 \pm 10\end{array}$ & $\begin{array}{l}0.72 \\
0.80\end{array}$ & $\begin{array}{c}100 \pm 8 \\
63.7 \pm 7.5\end{array}$ & $\begin{array}{c}1.73 \pm 0.03 \text { (in ppmv) } \\
8,500 \pm 3525\end{array}$ & $\begin{array}{l}0.60 \\
0.70\end{array}$ & $\begin{array}{c}94 \pm 13 \\
\text { na }\end{array}$ & $\begin{array}{c}0.70 \\
\text { na }\end{array}$ \\
\hline $\begin{array}{l}\text { Ethane } \\
\text { Ethene } \\
\text { Ethyne }\end{array}$ & $\begin{array}{c}5.2 \pm 0.7 \\
11 \pm 1 \\
2.4 \pm 0.4\end{array}$ & $\begin{array}{l}0.85 \\
0.83 \\
0.63\end{array}$ & $\begin{array}{l}4.9 \pm 0.4 \\
3.9 \pm 0.7 \\
2.1 \pm 0.2\end{array}$ & $\begin{array}{c}613 \pm 212 \\
<8 \\
92 \pm 82\end{array}$ & $\begin{array}{l}0.72 \\
0.53 \\
0.77\end{array}$ & $\begin{array}{l}8.3 \pm 0.3 \\
6.1 \pm 0.4 \\
3.3 \pm 0.1\end{array}$ & $\begin{array}{l}0.97 \\
0.87 \\
0.97\end{array}$ \\
\hline $\begin{array}{l}\text { Propane } \\
\text { Propene } \\
\text { Propadiene }\end{array}$ & $\begin{array}{c}1.0 \pm 0.1 \\
3.9 \pm 0.3 \\
0.10 \pm 0.09\end{array}$ & $\begin{array}{l}0.82 \\
0.87 \\
0.82\end{array}$ & $\begin{array}{l}0.78 \pm 0.09 \\
0.28 \pm 0.13 \\
0.03 \pm 0.03\end{array}$ & $\begin{array}{c}35 \pm 37 \\
54 \pm 55 \\
<8\end{array}$ & $\begin{array}{c}0.70 \\
0.12 \\
\text { bdl }\end{array}$ & $\begin{array}{c}1.6 \pm 0.1 \\
0.4 \pm 0.1 \\
\mathrm{na}\end{array}$ & $\begin{array}{c}0.95 \\
0.62 \\
\mathrm{na}\end{array}$ \\
\hline $\begin{array}{l}i \text {-butane } \\
n \text {-butane } \\
1 \text {-butene } \\
t-2 \text {-butene } \\
c-2 \text {-butene }\end{array}$ & $\begin{array}{l}0.07 \pm 0.01 \\
0.21 \pm 0.02 \\
0.66 \pm 0.06 \\
0.26 \pm 0.02 \\
0.22 \pm 0.02\end{array}$ & $\begin{array}{l}0.82 \\
0.79 \\
0.90 \\
0.89 \\
0.89\end{array}$ & $\begin{array}{c}0.046 \pm 0.007 \\
0.12 \pm 0.03 \\
0.09 \pm 0.03 \\
<0.01 \\
<0.01\end{array}$ & $\begin{array}{l}7 \pm 3 \\
12 \pm 7 \\
<8 \\
<8 \\
<8\end{array}$ & $\begin{array}{c}0.54 \\
0.63 \\
0.08 \\
\text { bdl } \\
\text { bdl }\end{array}$ & $\begin{array}{c}0.055 \pm 0.02 \\
0.21 \pm 0.01 \\
\mathrm{na} \\
\mathrm{na} \\
\mathrm{na}\end{array}$ & $\begin{array}{c}0.55 \\
0.21 \\
\text { na } \\
\text { na } \\
\text { na }\end{array}$ \\
\hline $\begin{array}{l}i \text {-pentane } \\
n \text {-pentane }\end{array}$ & $\begin{array}{l}0.03 \pm 0.004 \\
0.06 \pm 0.006\end{array}$ & $\begin{array}{l}0.73 \\
0.81\end{array}$ & $\begin{array}{l}<0.01 \\
<0.01\end{array}$ & $\begin{array}{l}<8 \\
<8\end{array}$ & $\begin{array}{l}\text { bdl } \\
\text { bdl }\end{array}$ & $\begin{array}{c}\mathrm{na} \\
0.05 \pm 0.01\end{array}$ & $\begin{array}{c}\mathrm{na} \\
0.80\end{array}$ \\
\hline $\begin{array}{l}\text { Benzene } \\
\text { Toluene } \\
\text { Ethylbenzene } \\
o \text {-xylene } \\
m \text {-xylene } \\
p \text {-xylene }\end{array}$ & $\begin{array}{c}1.5 \pm 0.2 \\
0.9 \pm 0.1 \\
0.10 \pm 0.01 \\
0.05 \pm 0.005 \\
0.11 \pm 0.01 \\
0.06 \pm 0.005\end{array}$ & $\begin{array}{l}0.89 \\
0.81 \\
0.70 \\
0.62 \\
0.72 \\
0.72\end{array}$ & $\begin{array}{c}1.2 \pm 0.09 \\
0.44 \pm 0.09 \\
<0.01 \\
<0.01 \\
<0.01 \\
<0.01\end{array}$ & $\begin{array}{c}10 \pm 38 \\
9 \pm 36 \\
<8 \\
<8 \\
<8 \\
<8\end{array}$ & $\begin{array}{l}0.85 \\
0.48 \\
\text { bdl } \\
\text { bdl } \\
\text { bdl } \\
\text { bdl }\end{array}$ & $\begin{array}{c}1.29 \pm 0.05 \\
0.57 \pm 0.03 \\
\mathrm{na} \\
0.03 \pm 0.002 \\
0.04 \pm 0.004 \\
0.02 \pm 0.003\end{array}$ & $\begin{array}{c}0.97 \\
0.93 \\
\mathrm{na} \\
0.87 \\
0.83 \\
0.93\end{array}$ \\
\hline Isoprene & $0.07 \pm 0.01$ & 0.73 & $<0.01$ & $<8$ & bdl & na & na \\
\hline $\begin{array}{l}\mathrm{CH}_{3} \mathrm{Cl} \\
\mathrm{CHCl}_{3} \\
\mathrm{CH}_{3} \mathrm{I} \\
\mathrm{CH}_{3} \mathrm{Br} \\
\mathrm{CHBr}_{3}\end{array}$ & $\begin{array}{c}0.52 \pm 0.17 \\
0.001 \pm 1 \mathrm{e}-3 \\
0.005 \pm 1 \mathrm{e}-3 \\
0.01 \pm 3 \mathrm{e}-3 \\
-1 \mathrm{e}-4 \pm 1 \mathrm{e}-4\end{array}$ & $\begin{array}{l}0.56 \\
0.63 \\
0.30 \\
0.65 \\
0.07\end{array}$ & $\begin{array}{c}0.42 \pm 0.05 \\
0.003 \pm 1 \mathrm{e}-3 \\
0.003 \pm 2 \mathrm{e}-3 \\
0.004 \pm 3 \mathrm{e}-3 \\
0.001 \pm 2 \mathrm{e}-3\end{array}$ & $\begin{array}{c}602+25 \\
7 \pm 0.5 \\
1 \pm 1 \\
12 \pm 1 \\
1.5 \pm 0.8\end{array}$ & $\begin{array}{l}0.52 \\
0.11 \\
0.03 \\
0.02 \\
0.02\end{array}$ & $\begin{array}{c}0.85 \pm 0.06 \\
\mathrm{na} \\
0.001 \pm 2 \mathrm{e}-4 \\
0.01 \pm 1 \mathrm{e}-3 \\
\text { na }\end{array}$ & $\begin{array}{c}0.88 \\
\text { na } \\
0.57 \\
0.88 \\
\text { na }\end{array}$ \\
\hline
\end{tabular}

Units for emission ratios are change of species concentration (in parts per trillion volume (pptv)) per change in CO (in parts per billion volume (ppbv)). Also shown for SCAR-B are estimates of the natural "background" concentrations; bdl, below detectable limits; na, not available.

into $\mathrm{CO}_{2}$ or $\mathrm{CO}$, transformed into large or reactive molecules, which were not detectable by the gas chromatograph, removed from the atmosphere, and/or transformed into particulate matter.

Carbon can be removed from the atmosphere by wet and dry deposition. Since cumulonimbus clouds were present in Porto Velho and Marabá, some wet deposition may have occurred. However, since precipitating clouds were isolated, it is unlikely that they played a major role in carbon deposition.

Dry deposition of the reactive hydrocarbons is a more likely removal process. Intense solar radiation in the tropics probably transforms many of the hydrocarbons emitted from fires into very reactive species. Reactive gas species have dry deposition velocities of the order of $1 \mathrm{~cm} \mathrm{~s}^{-1}$ [Sehmel, 1980], which could cause hydrocarbon losses of the magnitude we measured in about 2 days. Dry deposition rates would have been substantially enhanced by the considerable amount of surface area of vegetation in the forests. On the other hand, the atmosphere was frequently decoupled with an inversion separating the mixed and convective boundary layers. Furthermore, during early morning flights, a very strong nocturnal boundary layer was observed. Such inversions would substantially reduce the flux of hydrocarbons from the CBL to the surface. As will be discussed later, there is also evidence that a significant fraction of the depleted carbon in the NMHC was converted to particulate matter.

On average, the ratio of alkanes to $\mathrm{CO}$ were reduced by $30 \%$ during the evolution of the smoke from fires to regional haze. Because alkanes are generally nonreactive and have low solubilities, it is unlikely they were removed from the atmosphere through wet or dry deposition; more likely, they were transformed into other species such as $\mathrm{CO}_{2}, \mathrm{CO}$, and oxygenates by photochemical or free radical reactions. Emission ratios for alkenes and aromatics dramatically decreased during plume evolution: $75-100 \%$ of the measured alkenes and $25-100 \%$ of the identified aromatics were transformed into other species or removed during evolution.

Correlation coefficients between stable species, such as 

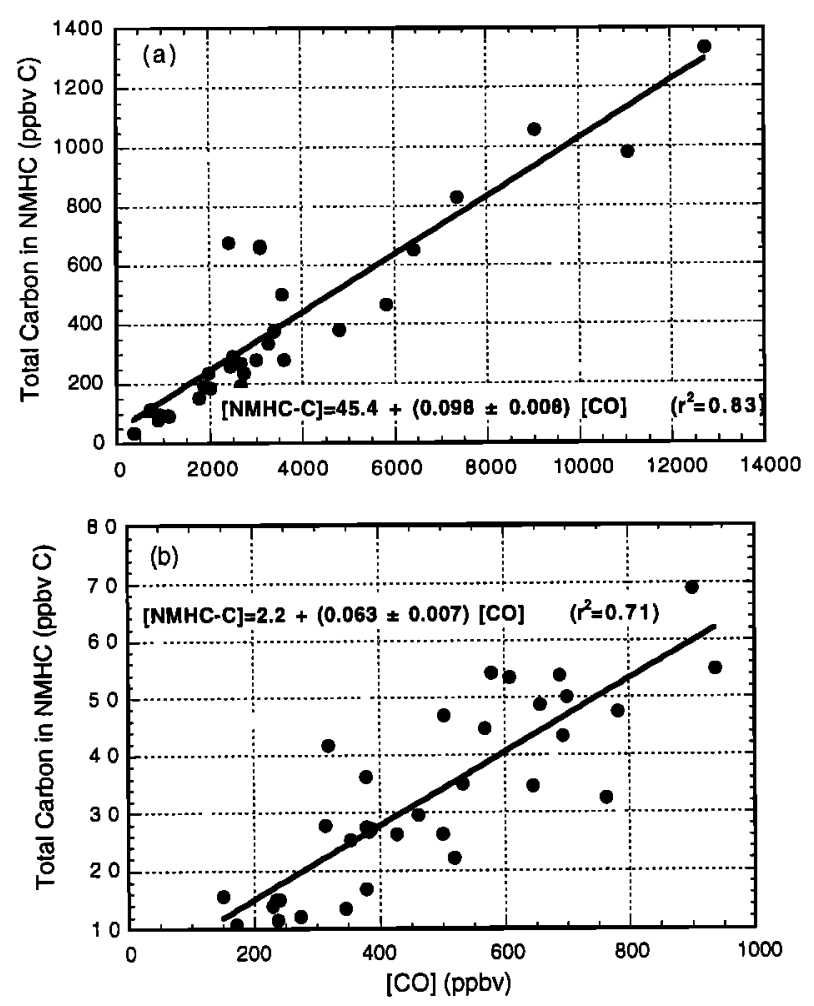

Figure 2. Regressions of total carbon in nonmethane hydrocarbon (NMHC) species to $\mathrm{CO}$ for (a) young smoke from Ferek et al. [this issue] and (b) regional hazes dominated by smoke in Brazil.

ethane and benzene, and $\mathrm{CO}$ were good $\left(r^{2}>0.6\right)$. However, for the more reactive species, correlation coefficients were low (typically $r^{2}<0.5$ ). This was probably due to the varying histories of the air parcels sampled. Alkenes and aromatics (other than benzene) typically have very short photochemical lifetimes, ranging from under an hour for butenes to days for toluene [Finlayson-Pitts and Pitts, 1986]. Thus the age of a sampled air parcel should have a large effect on the ratio of a reactive species to $\mathrm{CO}$.

Included in Table 3 are estimates of the background concentrations of the hydrocarbons. By "background" we mean the concentration of gases that would likely exist if the atmosphere had not been perturbed by biomass burning. The background concentrations of hydrocarbons were found by extrapolating the hydrocarbon versus $\mathrm{CO}$ regression line to a $\mathrm{CO}$ value of $100 \mathrm{ppbv}$ (a typical $\mathrm{CO}$ value for continental air masses). As can be seen in Table 3, the concentrations of many of the hydrocarbons were strongly influenced by biogenic or other regional emissions. On average, $20 \%$ of the carbon (approximately $8 \mathrm{ppbc}$ ) in the form of NMHC in the atmosphere was associated with sources other than combustion. The predominant background species were ethane, ethyne, butane, benzene, and toluene. These background values are in reasonable agreement with the results of Zimmerman et al. [1988] in the Amazon.

The strongest halocarbons associated with biomass buming were $\mathrm{CH}_{3} \mathrm{Cl}, \mathrm{CHCl}_{3}, \mathrm{CH}_{3} \mathrm{I}$, and $\mathrm{CH}_{3} \mathrm{Br}$ [Ferek et al., this issue]. $\mathrm{CH}_{3} \mathrm{Cl}, \mathrm{CHCl}_{3}$, and $\mathrm{CH}_{3} \mathrm{I}$ did not show any statistically significant reduction during evolution to regional hazes. However, the ratio of $\mathrm{CH}_{3} \mathrm{Br}$ to $\mathrm{CO}$ decreased by a factor of 2 .
Furthermore, correlations of $\mathrm{CH}_{3} \mathrm{Br}$ and $\mathrm{CH}_{3} \mathrm{I}$ with $\mathrm{CO}$ were extremely low $\left(r^{2}<0.05\right)$, indicating either reactions in the atmosphere or the existence of other significant sources.

All of the halocarbon species had relatively high background concentrations in the regional hazes. For example, we estimate that the background concentration of methyl chloride was about 600 pptv. However, on the most polluted days the methyl chloride concentration was perturbed by 300-500 pptv. Thus about one third to one half of the methyl chloride and methyl iodide in the regional hazes can be attributed to biomass burning. Biomass burning contributed less than $30 \%$ to the methyl bromide in the regional hazes.

Most of the ratios of the hydrocarbons and halocarbons to CO measured in regional hazes in SCAR-B are similar (within $20 \%$ ) to those measured in haze layers over Brazil during TRACE A [Blake et al., 1996]. However, there are significant differences between our ratios of alkenes and $\mathrm{CH}_{3} \mathrm{Cl}$ to those reported by Blake et al. For the alkenes the difference is attributed to their high dependence on plume age. As discussed above, alkenes have photochemical lifetimes of the order of hours to days. Blake et al. performed measurements on only a few plumes in a different part of the continent; it is likely that the hazes had different ages than those we studied.

The $\mathrm{CH}_{3} \mathrm{Cl}$ ratio reported by Blake et al. [1996] are slightly higher than the values for young smoke given in Table 3 and by Ferek et al. [this issue]. Because similar apparatus, protocols, and standards were used in both studies, the difference is likely due to sampling emphasis. The gas ratios given in the present paper are based on many measurements in regional hazes at three locations in Brazil. Similarly, the results from Ferek et al. [this issue] are for measurements on 25 individual fires at the same three locations for which data are presented in this paper. Therefore the results presented here and by Ferek et al. [this issue] are for the ensemble average of many fires and plume histories. The TRACE A results, on the other hand, are based on samples from a much smaller number of haze layers. McKenzie et al. [1997] report that $\mathrm{CH}_{3} \mathrm{Cl} / \mathrm{CO}$ for smoke from biomass fires is predominantly a function of the chlorine content of the fuel, which is particularly high in savanna grasses compared to forest material. Different individual fuel conditions might perturb the emissions of $\mathrm{CH}_{3} \mathrm{Cl}$ and $\mathrm{CO}$ more than those of the hydrocarbons, making the relatively small number of samples collected in Brazil in TRACE A more vulnerable to being unrepresentative of the region.

\section{Particle Properties}

\subsection{Size Distributions}

A summary of the particle size distribution parameters, derived from the DMPS and PCASP, is given in Table 4. The particle size distributions varied greatly by region. Overall, there were trends of increasing particle size and decreasing standard deviations with increasing smoke age. For example, the largest particles where associated with hazes over Porto Velho and the well-aged smoke episode over Cuiabá ( $\triangle C M D$ and $\triangle V M D$ of $0.06 \mu \mathrm{m}$ and $0.08 \mu \mathrm{m}$, respectively). Conversely, regions and time periods associated with predominately local smoke, for example in Marabá, had particle count median diameters and volume median diameters ( $C M D$ and $V M D$, respectively) of only 0.01 to $0.02 \mu \mathrm{m}$ greater than for young smoke. 
Table 4. Aerosol Particle Size Distribution Parameters (Mean \pm Standard Deviation) for Cuiabá (Local Haze), Cuiabá (Aged Haze), Porto Velho, and Marabá

\begin{tabular}{lccccc}
\hline Parameter & Young Smoke & $\begin{array}{c}\text { Cuiabá } \\
\text { (Local) }\end{array}$ & $\begin{array}{c}\text { Cuiabá } \\
\text { (Aged) }\end{array}$ & Porto Velho & Marabá \\
\hline$C M D(\mu \mathrm{m})$ (from DMPS) & $0.12 \pm 0.02$ & $0.13 \pm 0.04$ & $0.18 \pm 0.02$ & $0.18 \pm 0.03$ & $0.11 \pm 0.02$ \\
$\sigma_{g c}$ (from DMPS) & $1.73 \pm 0.07$ & $1.74 \pm 0.13$ & $1.68 \pm 0.16$ & $1.63 \pm 0.16$ & $1.85 \pm 0.17$ \\
$V M D(\mu \mathrm{m})($ from DMPS) & $0.26 \pm 0.02$ & $0.28 \pm 0.05$ & $0.35 \pm 0.04$ & $0.34 \pm 0.07$ & $0.30 \pm 0.04$ \\
$\sigma_{g \nu}($ from DMPS) & $1.73 \pm 0.06$ & $1.58 \pm 0.08$ & $1.48 \pm 0.07$ & $1.51 \pm 0.10$ & $1.64 \pm 0.30$ \\
$C M D(\mu \mathrm{m})$ (from PCASP) & $\mathrm{na}$ & $0.15 \pm 0.03$ & $0.21 \pm 0.01$ & $0.21 \pm 0.03$ & $0.13 \pm 0.03$ \\
$\sigma_{g c}$ (from PCASP) & na & $1.6 \pm 0.08$ & $1.56 \pm 0.06$ & $1.55 \pm 0.09$ & $1.83 \pm 0.21$ \\
$V M D(\mu \mathrm{m})$ (from PCASP) & $\mathrm{na}$ & $0.25 \pm 0.02$ & $0.30 \pm 0.01$ & $0.29 \pm 0.02$ & $0.27 \pm 0.01$ \\
$\sigma_{g \nu}$ (from PCASP) & $\mathrm{na}$ & $1.34 \pm 0.07$ & $1.24 \pm 0.02$ & $1.26 \pm 0.04$ & $1.35 \pm 0.05$ \\
\hline
\end{tabular}

Also shown are the particle size parameters for young smoke from biomass buming from Reid and Hobbs [this issue] assuming an MCE of 0.89 . CMD, count median diameter; VMD, volume median diameter; $\sigma_{g}$, geometeric standard deviation; na, not available.

Table 4 shows some differences between the particle sizes from the DMPS and PCASP. Regression relations between DMPS and PCASP measurements are given in Table 5. As indicated by the low correlation coefficients for these regressions, there was a significant amount of scatter in the measurements. The $C M D$ from the PCASP is $10 \%$ greater than those generated by the DMPS (albeit not statistically significantly). Conversely, the VMD and standard deviations measured by the DMPS are $10 \%$ greater than those from the PCASP. There are several possible reasons for these differences. In particular, the PCASP measurements depend on the scattering properties of the aerosol, while the DMPS measurements are based on particle electromobility. The response function of the PCASP is highly sensitive to refractive index for aerosols in the diameter range $0.3-0.8 \mu \mathrm{m}$. If the particles have a refractive index that is lower than the assumed value of 1.5-0.02i, the PCASP will underestimate the particle volume median diameter and standard deviation. Also, derivation of particle sizes from the DMPS requires an inversion, which may artificially increase the $V M D$ and $\sigma_{g v}$ values [Winklmayr et al., 1991]. Finally, the DMPS samples were from the grab bag, where the relative humidity was similar (perhaps slightly lower due to increased cabin temperature) to that of the ambient air. The PCASP, on the other hand, dries the aerosol to a humidity $<35 \%$, which should remove any water or high-volatility hydrocarbons.

Table 5. Regression Relations Between Lognormal Particle Fit Parameters Derived From the DMPS and PCASP Particle Sizir.g Instruments for All Data Obtained From the UW C-131A Aircraft in Regional Hazes in Brazil

\begin{tabular}{lll}
\hline Parameter & Relationship & $r^{2}$ \\
\hline$C M D$ & DMPS $=-0.005+0.82 \times$ PCASP & 0.57 \\
$\sigma_{g c}$ & DMPS $=0.605+0.69 \times$ PCASP & 0.56 \\
$V M D$ & & \\
$\sigma_{g v}$ & DMPS $=0.016+1.07 \times$ PCASP & 0.40 \\
\hline
\end{tabular}

$r$, correlation coefficient.
However, since the smoke particles encountered in SCAR-B had low-humidification factors [Kotchenruther and Hobbs, this issue], drying should have caused no more than a $0.02 \mu \mathrm{m}$ decrease in the particle $V M D$. The actual ambient aerosol size distribution is likely to lie somewhere between the DMPS and PCASP measurements. Because the PCASP dries the aerosol and has a significantly higher sampling frequency than the DMPS, we will concentrate on the measurements from the PCASP in the remainder of this paper.

Particle number and volume distributions typical of regional hazes dominated by smoke are shown in Figure 3.
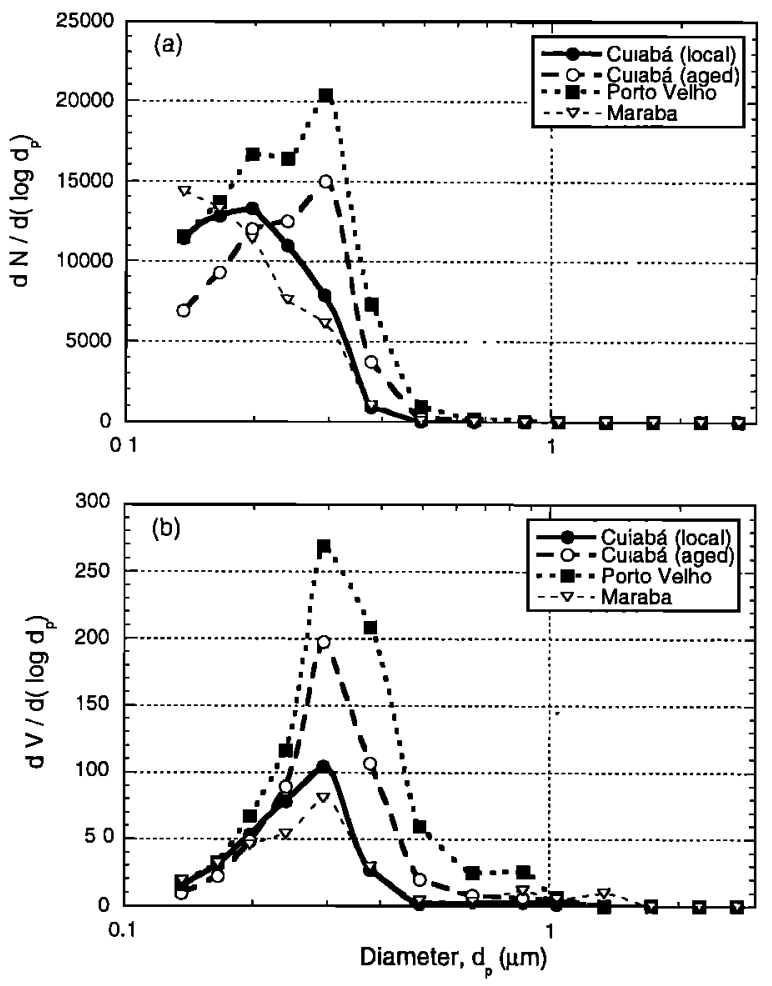

Figure 3. Typical (a) particle number and (b) particle volume distributions measured near $800 \mathrm{hPa}$ in regional hazes dominated by smoke near Cuiabá, Porto Velho, and Marabá. 

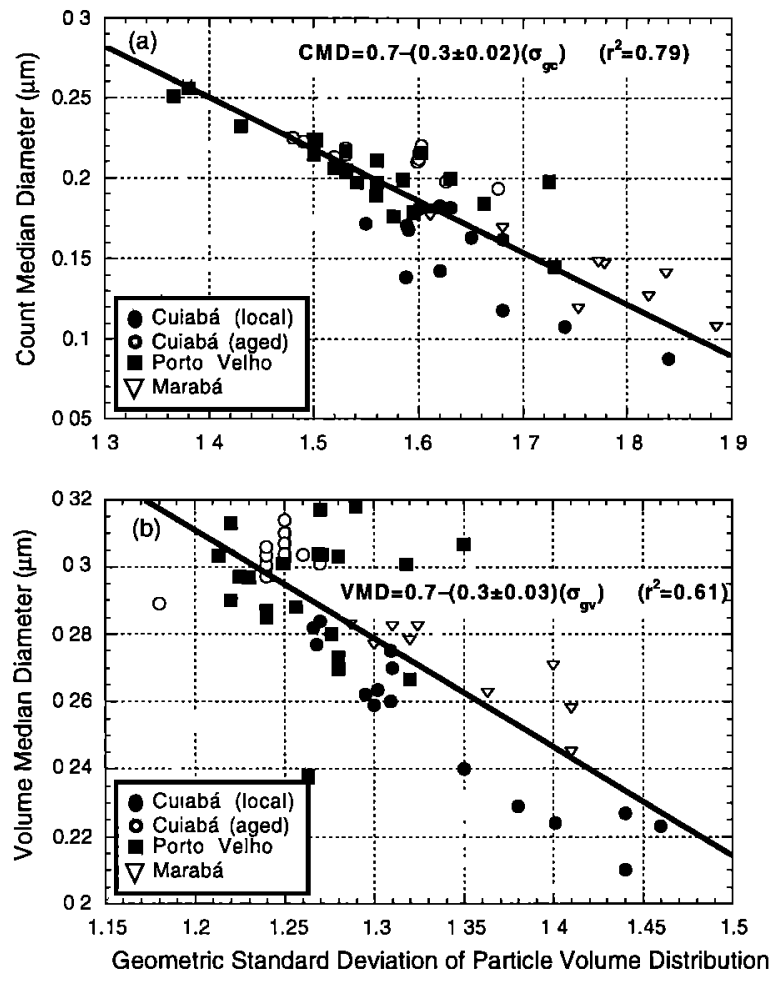

Figure 4. (a) Count median diameter (CMD) versus geometric standard deviation $\left(\sigma_{g c}\right)$ for particle number distribution and (b) volume median diameter $(V M D)$ versus geometric standard deviation $\left(\sigma_{g \nu}\right)$ for particle volume distribution, for regional hazes dominated by smoke in Brazil.

The number distributions show a clear distinction between young and aged smoke. In the Cuiabá (local) case, the particle number distribution is essentially lognormal, and the particle sizes are small. In Marabá the particle sizes are also small, with a modal diameter $<0.12 \mu \mathrm{m}$. Both of these number distributions are similar to those for the young smoke [Reid and Hobbs, this issue]. For the aged smoke in Cuiaba and Porto Velho the particle number distributions have a ramp-like structure, with two significant modes at 0.2 and $0.3 \mu \mathrm{m}$ diameter. Because of this shape, the $C M D$ determined by the lognormal curve fit was $0.04 \mu \mathrm{m}$ smaller than the count distribution mode. Because these modes are almost twice as large as the CMD reported by Reid and Hobbs [this issue] for young smoke, it is likely they were produced as the smoke evolved into the regional haze.

There were also significant differences in the particle volume distributions of the young and aged smoke. In aged smoke, the volume distribution was nearly lognormal. However, the volume distributions of the Cuiaba (local) and Marabá cases were somewhat ramp shaped.

As the median diameters of the particles increased, there was a tendency for the standard deviations to narrow during smoke aging (Figure 4). This tendency was particularly strong for the younger hazes, such as the Cuiabá (local) and Marabá cases. There are also strong anticorrelations between the particle count median diameter and the standard deviation for the number distributions measured with the DMPS.

The particle size distributions varied slightly with altitude. As an example, plots of particle number and volume distributions at three pressure levels $(650,800$, and $970 \mathrm{hPa})$ are shown in Figure 5. These data were collected in a vertical profile in well-aged regional haze near Porto Velho. The measurements at $650 \mathrm{hPa}$ level $(\sim 4 \mathrm{~km})$ were above the haze layer in the free troposphere. Here the aerosol concentrations are low $\left(<10 \mu \mathrm{g} \mathrm{m}^{-3}\right)$ and the size distribution broad. However, the number distribution exhibits the same bimodal nature as the aged smoke shown in Figure 3. The $800 \mathrm{hPa}$ flight level was at the top of the mixed layer. Here, the particle concentration are high $\left(>150 \mu \mathrm{g} \mathrm{m}^{-3}\right)$, and the number distribution takes on the ramp-like shape of the aged smoke shown in Figure 3. At the base of the mixed layer $(970 \mathrm{hPa}$ level) the particle mass concentration and size distribution were generally similar to those at the top of the mixed layer. However, there was a significant increase in the number of particles with diameters less than $0.14 \mu \mathrm{m}$ diameter. An increase in the number of particles of this size was always observed when sampling near the surface in forested regions. Hence they may have a biogenic origin. The perturbations in the particle number distributions did not have an appreciable effect on the volume distributions.

\subsection{Compositions}

A summary of the ionic compositions of the particles in the young smoke and in the regional hazes is given in Table 6. Also shown in this table are the percentages of black carbon in the aerosol from thermal evolution analysis and Fe from PIXE. Of the 62 samples subjected to IC analysis, 41 were analyzed by PIXE for Fe and 38 for black carbon.

The data in Table 6 show that the compositions of the particles in the regional hazes were significantly different
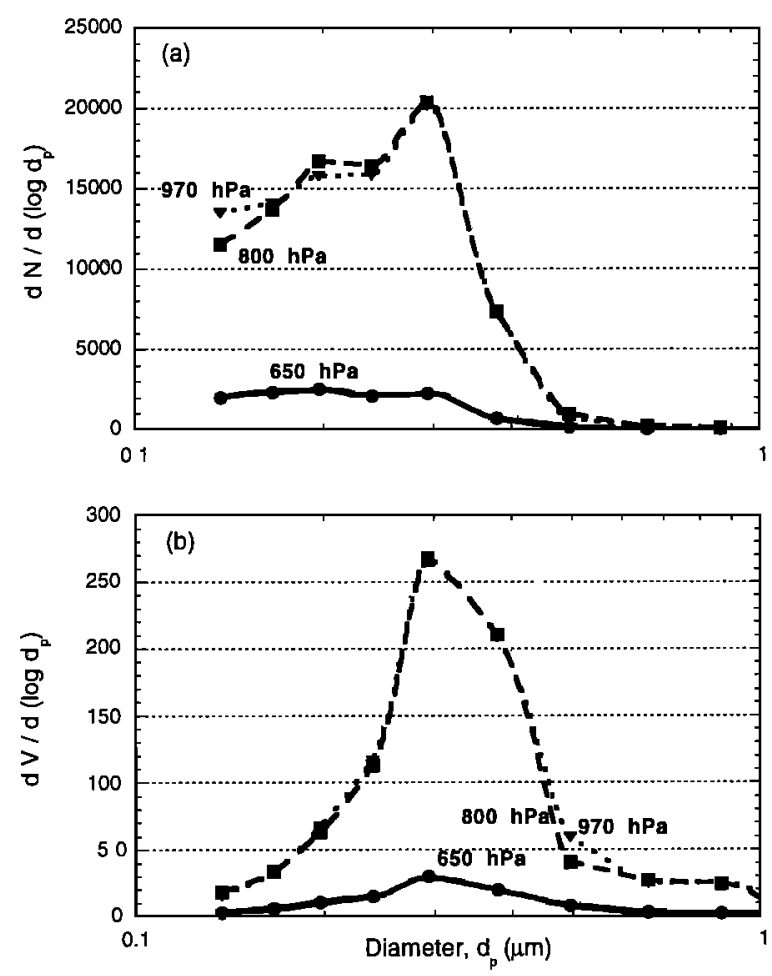

Figure 5. (a) Particle number and (b) particle volume distributions measured at three pressure levels in a profile flight over the NASA Jamari Sun photometer site near Porto Velho in regional haze dominated by smoke. 
Table 6. Percentage Speciation of Aerosol Mass (Mean \pm Standard Deviation) and Mass Apportionment From Principal Component Analysis for Cuiabá (Local Haze), Cuiabá (Aged Haze), Porto Velho, and Marabá

\begin{tabular}{|c|c|c|c|c|c|}
\hline & Young Smoke & $\begin{array}{l}\text { Cuiabá } \\
\text { (Local) }\end{array}$ & $\begin{array}{l}\text { Cuiabá } \\
\text { (Aged) }\end{array}$ & Porto Velho & Marabá \\
\hline \multicolumn{6}{|c|}{ Percentage Speciation } \\
\hline Black carbon (TE) & $6.6 \pm 3.0$ & -8 & $6.6 \pm 3.0$ & $5.6 \pm 2.8$ & $8.0 \pm 2.5$ \\
\hline $\mathrm{Ca}^{2+}$ & $0.8 \pm 0.8$ & $0.45 \pm 0.3$ & $0.1 \pm 0.1$ & $0.3 \pm 0.6$ & $0.6 \pm 0.3$ \\
\hline $\mathrm{C}^{-}$ & $1.1 \pm 1.2$ & $0.12 \pm 0.2$ & $0.01 \pm 0.02$ & $0.2 \pm 0.5$ & $0.8 \pm 1.0$ \\
\hline $\mathrm{K}^{+}$ & $3.7 \pm 3.0$ & $1.47 \pm 0.7$ & $1.6 \pm 0.4$ & $1.9 \pm 0.7$ & $2.3 \pm 0.5$ \\
\hline $\mathrm{Mg}^{2+}$ & $0.45 \pm 0.1$ & $0.2 \pm 0.3$ & $0.03 \pm 0.05$ & $0.1 \pm 0.3$ & $0.1 \pm 0.1$ \\
\hline $\mathrm{Na}^{+}$ & $0.15 \pm 0.1$ & $0.1 \pm 0.1$ & $0.1 \pm 0.1$ & $0.4 \pm 0.7$ & $0.8 \pm 0.4$ \\
\hline $\mathrm{NH}_{4}^{+}$ & $0.15 \pm 0.25$ & $0.5 \pm 0.3$ & $1.8 \pm 0.7$ & $2.0 \pm 0.7$ & $1.3 \pm 0.9$ \\
\hline $\mathrm{NO}_{3}^{\frac{7}{3}}$ & $0.75 \pm 0.25$ & $1.5 \pm 0.9$ & $1.6 \pm 1.0$ & $1.2 \pm 0.9$ & $1.1 \pm 0.6$ \\
\hline $\mathrm{C}_{2} \mathrm{O}_{4}^{=}$ & $0.55 \pm 0.25$ & $1.2 \pm 0.8$ & $1.5 \pm 0.4$ & $2.0 \pm 0.6$ & $1.3 \pm 0.6$ \\
\hline $\mathrm{PO}_{4}^{-}$ & $0.03 \pm 0.04$ & $0.01 \pm 0.01$ & $0.01 \pm 0.01$ & $0.02 \pm 0.06$ & BDL \\
\hline $\mathrm{SO}_{4}^{2}$ & $2.5 \pm 1.5$ & $1.3 \pm 0.8$ & $4.0 \pm 1.6$ & $7.6 \pm 3.2$ & $6.8 \pm 2.6$ \\
\hline Fe (PIXE) & na & $0.5 \pm 0.3$ & $0.4 \pm 0.2$ & $0.6 \pm 0.4$ & $0.6 \pm 0.7$ \\
\hline Residue* & $82.3 \pm 0.5$ & $84.3 \pm 1$ & $82.1 \pm 0.2$ & $77.8 \pm 0.6$ & $75.7 \pm 0.5$ \\
\hline \multicolumn{6}{|c|}{ Mass Apportionment, $\%_{0}$} \\
\hline Soil & & $10 \pm 6$ & $8 \pm 4$ & $12 \pm 8$ & $12+15$ \\
\hline Biogenic & & $7 \pm 3$ & $1 \pm 1$ & $4 \pm 6$ & $5 \pm 3$ \\
\hline Biomass buming & & $67 \pm 5$ & $65 \pm 5$ & $62 \pm 5$ & $66 \pm 10$ \\
\hline Residual & & $16 \pm 6$ & $26 \pm 4$ & $22 \pm 8$ & $17 \pm 15$ \\
\hline
\end{tabular}

Also shown are average values for young smoke from biomass buming [from Ferek et al., this issue] assuming an MCE of 0.89 .

*The residue is the difference between the measured total aerosol mass $(<4 \mu \mathrm{m}$ diameter) and that accounted for by the measured species; it is probably mostly organics.

from that of young smoke. In particular, the regional hazes had much higher mass fractions of secondary aerosol products, such as sulfate, oxalate, ammonium, and nitrate. Conversely, the mass fractions of primary (or tracer) species from biomass burning (such as black carbon, potassium, and chloride) were less in the regional hazes than in the young smoke. More than $70 \%$ of the aerosol mass was unaccounted for by the ionic and other species listed in Table 4. The large "residue" was presumed to be mainly organics.

The mass fraction of black carbon in the aerosol is in the range $5-8 \%$. The black carbon contents of the aged Cuiaba and Porto Velho hazes were generally $10-20 \%$ lower than that of the young smoke. Hazes containing less aged smoke, such as those in Marabá, had black carbon contents similar to young smoke. However, the black carbon concentrations were very variable and were measured with low precision, so the differences in black carbon contents between the three regions and with smoke age are not statistically significant. It is clear, however, that the black carbon content of the regional hazes was, on average, $6 \pm 3 \%$ of the total particle mass.

What fraction of the aerosol in the regional hazes was due to biomass burning? The composition of the aerosol in the Amazon Basin can be divided into five possible components: primary smoke products, secondary smoke products, other anthropogenic materials, biogenic materials, and soils. Artaxo et al. [this issue] was able to separate these components in the Amazon Basin through an APCA. However, the relative contributions of these components to the aerosol mass loading is highly variable, and we need to be assured that the regional hazes sampled from the C-131A aircraft were dominated by smoke. Because of the low aerosol mass loadings on the filters used in this study, relatively few elemental and ionic species could be identified. However, an attempt was made to separate the aerosol components through an APCA to see if our results are qualitatively similar to those of Artaxo et al. The PCA included filter data from all regions and the species shown in Table 6. The VARIMAX rotation scheme was employed to minimize the number of variables that have high loadings on a factor [Norusis, 1994]. The aerosol specific absorption $\left(\alpha_{a}\right)$ was used as a surrogate for the black carbon concentration because of the high variability of the latter. The aerosol "residue" was also included in the PCA.

Factor eigenvalues $(\lambda)$ and loadings for the PCA are given in Table 7. The PCA generated three orthogonal factors (compared to five by Artaxo et al. [this issue]). The strongest factor $(\lambda=5.0)$ was well correlated with particle absorption, potassium and iron, as well as with most of the secondary aerosol species such as ammonium, oxalate, and sulfate. Furthermore, this factor was the only one that was highly correlated with the "residue." This factor is likely the sum of biomass burning, soils, and other combustion-related anthropogenic emissions. Because there was only one soil element in the analysis ( $\mathrm{Fe}$ ) the PCA was unable to extract a separate soil factor; hence the soils are imbedded in the first factor. Also, there may be an embedded soil component in biomass burning from soil entrained into the smoke plumes [Reid and Hobbs, this issue]. Thus biomass burning and soils may not necessarily be completely orthogonal components.

The second factor $(\lambda=2.5)$ is highly correlated with $\mathrm{Ca}^{2+}$ and $\mathrm{Mg}^{2+}$. Artaxo et al. [this issue] identified a similar factor and attributed it to biogenic emissions. Also, like Artaxo et al., we find that this factor is weakly (but statistically significantly) correlated with particle absorption. This lends credibility to Artaxo et al.'s suggestion that biogenic 
Table 7. Factor Analysis for Cuiabá (Local Haze), Cuiabá (Aged Haze), Porto Velho, and Marabá Using a VARIMAX Rotation

\begin{tabular}{lccc}
\hline & $\begin{array}{c}\text { Buming } \\
+ \text { Soil }\end{array}$ & Biogenics & $\mathrm{NaCl}$ \\
\hline Eigenvalue & 5.0 & 2.5 & 1.5 \\
$\alpha_{a}$ & $(0.79)$ & $(0.38)$ & -0.02 \\
$\mathrm{Ca}^{2+}$ & & & \\
$\mathrm{Cl}^{-}$ & -0.04 & $(0.91)$ & 0.18 \\
$\mathrm{Fe}$ & 0.02 & 0.24 & $(0.89)$ \\
$\mathrm{K}^{+}$ & $(0.67)$ & -0.10 & -0.04 \\
$\mathrm{Mg}^{2+}$ & $(0.87)$ & -0.04 & 0.30 \\
$\mathrm{Na}^{+}$ & -0.13 & $(0.91)$ & 0.09 \\
$\mathrm{NH}_{4}^{+}$ & -0.03 & 0.03 & $(0.95)$ \\
$\mathrm{NO}_{3}^{-}$ & $(0.90)$ & $(-0.37)$ & -0.02 \\
$\mathrm{C}_{2} 0_{4}^{-}$ & $(0.54)$ & 0.05 & 0.03 \\
$\mathrm{SO}_{4}^{-}$ & $(0.81)$ & $(-0.34)$ & -0.05 \\
$\mathrm{Residue}^{-}$ & $(0.72)$ & $(-0.39)$ & -0.02 \\
$\mathrm{APCA}^{4}$ & $(0.81)$ & 0.05 & -0.20 \\
$\mathrm{Apportionment}^{+}$ & $(100) \pm 5 \%$ & $(3) \pm 2 \%$ & $(-5) \pm 5 \%$ \\
\hline
\end{tabular}

Loadings with a confidence level $>95 \%$ are shown in parentheses. The last row lists the average absolute principal component analysis (APCA) mass apportionments for all samples.

emissions contain light absorption components that cannot be ignored.

The third factor $(\lambda=1.5)$ is associated with sodium chloride. This factor has a weak anticorrelation with the aerosol "residue," implying that when $\mathrm{NaCl}$ levels were high, the overall aerosol concentration was low. This could be interpreted as an indicator of an influx of marine air [Artaxo et al., 1994]. This factor was strongest in Marabá, which is within reasonable range of marine influences. However, this factor was also apparent as far inland as Cuiabá and Porto Velho. The SEM analysis of coarse particles did not reveal the existence of even one cubic-shaped $\mathrm{NaCl}$ crystal. Two of the 50 particles analyzed by EDX had extremely high $\mathrm{Na}$ and $\mathrm{Cl}$ concentrations, with no other elements detected. These particles had very irregular shapes and thus were likely associated with a specific soil or anthropogenic source. Also, $\mathrm{NaCl}$ is a common contaminant on aerosol samples. Since this factor is anticorrelated with the residue (and hence aerosol mass), the possibility that this factor is due to artifact cannot be ruled out.

Using the same APCA analysis as that used by Artaxo et al. [1994], the aerosol source apportionment attributable to the three factors discussed above were determined. The combustion and soil factors account for $100 \pm 5 \%$ of the total aerosol mass at all three locations. Biogenics accounted for only 1 to $5 \%$ of the mass. However, the mass balance was only obtained through negative apportionment $(-5 \%)$ attributed to the $\mathrm{NaCl}$ factor.

The inclusion of the soil component in the biomass buming factor, and low correlations between the aerosol mass and the biogenic and $\mathrm{NaCl}$ factor, makes a source apportionment using Artaxo et al.'s method for the regional hazes difficult. This difficulty is compounded by the unknown amount of soil asscciated with combustion and aeolean emissions. However, we can improve the source apportionment by performing a regression analysis on some key tracer species. The results of this analysis by region is shown at the bottom of Table 6 .

Iron accounts for $5 \pm 2 \%$ of suspended soils in Brazil [Artaxo et al., 1994, this issue] but less than $0.2 \%$ of biogenic and biomass emissions. Thus iron is an ideal tracer element for the soil component of the aerosol. The concentration of iron in individual aerosol samples ranged from 0.25 to $1 \%$. This implies that on average, $5-20 \%$ of the aerosol mass was from soil. The remaining $80-95 \%$ was likely associated with the biogenic and nonsoil components of the combustion.

The PCA analysis showed that the biogenic factor was well correlated with $\mathrm{Ca}^{2+}$ and $\mathrm{Mg}^{2+}$. Artaxo et al. [this issue] found that $\mathrm{Ca}^{2+}$ and $\mathrm{Mg}^{2+}$ account for 2.5 and $9 \%$ of the mass of biogenics, respectively. In comparison, $\mathrm{Ca}^{2+}$ and $\mathrm{Mg}^{2+}$ account for less than $1 \%$ of the mass of smoke and soil aerosols [Artaxo et al., this issue; Ferek et al., this issue]. Therefore $\mathrm{Ca}^{2+}$ and $\mathrm{Mg}^{2+}$ are reasonable tracers for biogenic aerosols. From Table 6 we see that $\mathrm{Ca}$ accounts for 0.1 to $0.6 \%$ of the aerosol mass in the regional hazes. This implies that biogenic species account for 1 to $7 \%$ of the aerosol mass. Similarly, $\mathrm{Mg}^{2+}$ accounts for 0.03 to $0.2 \%$ of the aerosol mass, which implies that biogenics account for 1.2 to $8 \%$ of the total aerosol mass. Since biomass burning and soil aerosols have $\mathrm{Ca}^{2+}$ and $\mathrm{Mg}^{2+}$ components, this apportionment is an upper bound.

Finally, we need to derive the amount of mass due to biomass burning. From the PCA the strongest candidate is $\mathrm{K}^{+}$, which accounted for $3.7 \%$ of the mass of the smoke from forest fires [Ferek et al., this issue]. Unfortunately, $\mathrm{K}^{+}$is also associated with soils, to which it contributes about $5 \%$ of the mass. Since we have shown that soil materials comprised at most $20 \%$ of the total aerosol mass, only a slight correction is necessary. In the regional hazes, $\mathrm{K}^{+}$accounted for 1.5 to $2.5 \%$ of the total aerosol mass. This implies that primary biomass burning emissions accounted for about 45 to $65 \%$ of the total aerosol mass.

Black carbon is also a strong candidate as a tracer for biomass burning. However, as discussed above, the BC measurements in the regional haze have a large uncertainty. Therefore we will use aerosol specific absorption $\left(\alpha_{a}\right)$. Since $\alpha_{a}$ is not strictly conserved during evolution (section 8 ), its use as a tracer of smoke will likely overestimate the amount of primary emissions from biomass burning. The average value of $\alpha_{a}$ for the forest fire smoke was $0.85 \mathrm{~m}^{2} \mathrm{~g}^{-1}$. For grass and cerrado fires it is approximately $1 \mathrm{~m}^{2} \mathrm{~g}^{-1}$. In the regional hazes, $\alpha_{a}$ ranged from 0.60 to $0.89 \mathrm{~m}^{2} \mathrm{~g}^{-1}$. This implies that roughly 70 to $90 \%$ of the aerosol mass was from primary emissions of biomass burning. The apportionment listed in Table 6 shows the average of the $\mathrm{K}^{+}$and $\alpha_{a}$ regressions.

In summary, the apportionment scale analysis shows that in the regional hazes we studied that roughly $10 \%$ of the aerosol was from soils, $5 \%$ from biogenics, and $65 \%$ from primary biomass burning aerosols. This leaves about $20 \%$ of the aerosol mass unaccounted for. Overall, one third of this $20 \%$ is attributable to secondary chemical species and the remainder to the (presumed organic) "residue."

Talbot et al. [1988] reported that the background mass concentration of coarse and fine aerosol in the Amazon Basin in the early part of the dry season (prior to significant biomass burning) was about $2-18 \mu \mathrm{g} \mathrm{m}^{-3}$. A significant portion of this probably derives from biogenic emissions. Furthermore, biomass burning and biogenic emissions are 

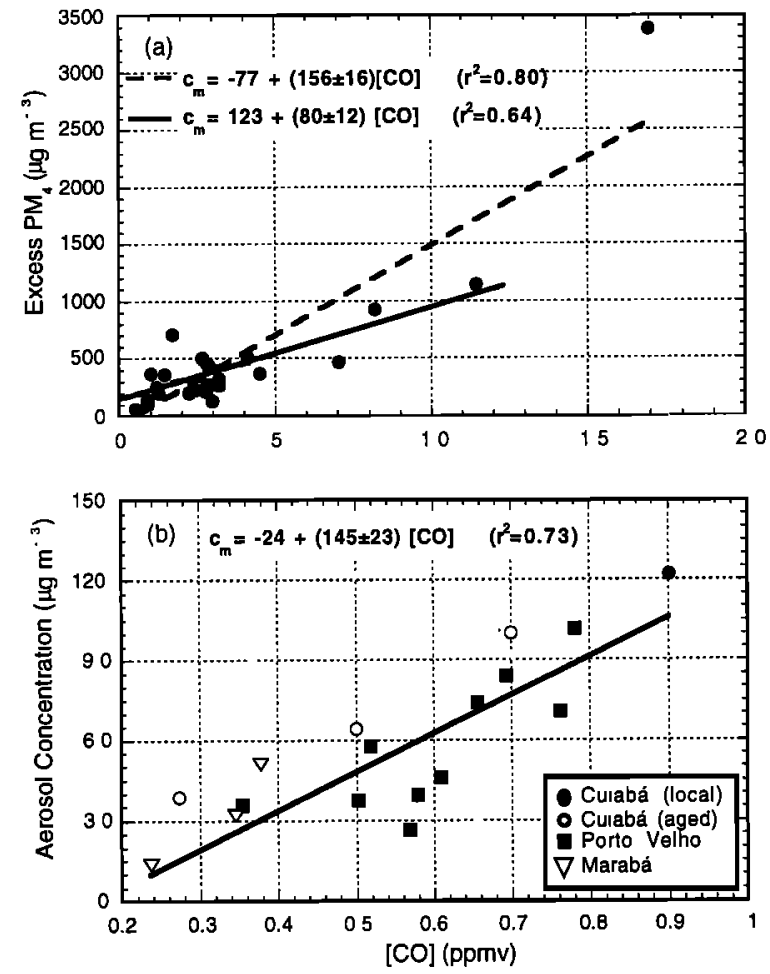

Figure 6. Total aerosol particle concentration $\left(c_{m}\right.$ in $\mu \mathrm{g}$ $\mathrm{m}^{-3}$ at STP) versus CO for (a) young smoke from Ferek et al. [this issue] and (b) regional hazes dominated by smoke in Brazil.

similar in chemical composition. Thus it is possible that a portion of the residual mass was due to biogenic emissions not accounted for in our regression analysis. However, if biogenic emissions had a significant impact on particle concentrations, this should manifest itself in regressions of particle concentration versus $\mathrm{CO}$ for young and aged smoke. Since vegetation does not emit $\mathrm{CO}$, the additional mass that correlates with $\mathrm{CO}$ is likely produced by combustion. This comparison is shown in Figure 6 for all of the emission factor data given by Ferek et al. [this issue]. The average MCE of these data points is 0.89 , which is similar to the average MCE for the regional hazes $(0.90)$. The slope of the regression for young smoke is $156 \pm 16 \mu \mathrm{g} \mathrm{m}^{-3} \mathrm{ppmv}^{-1}$, with an $r^{2}$ value of 0.79 (Figure 6a). Figure 6b shows a similar regression but for aerosol mass and $\mathrm{CO}$ data collected in the convective boundary layer in regional hazes. The slope of the aerosol mass/CO regression drops to $145 \pm 23 \mu \mathrm{g} \mathrm{m}^{-3} \mathrm{ppmv}^{-1}$, with a regression coefficient $\left(r^{2}\right)$ value of 0.72 . This implies that the mass of the aerosol decreases by $7 \%$ during aging, although this number is not statistically significant.

Figure 6a shows that the regression for the young smoke is heavily weighted by one extreme data point (at a $\mathrm{CO}$ concentration of $17 \mathrm{ppmv}$ ) collected in Marabá. This data point comes from the largest fire studied. As discussed by Ferek et al. [this issue], for large fires such as this, the particle-to-CO emission ratio can be several times greater than normal. If this one data point is removed, the slope of the aerosol mass-CO regression falls by almost factor of 2 , to $80 \pm 12 \mu \mathrm{g} \mathrm{m}^{-3} \mathrm{ppmv}^{-1}$, and the $r^{2}$ value remains high at 0.64 . This slope is similar to the value of $81 \mu \mathrm{g} \mathrm{m}^{-3} \mathrm{ppmv}^{-1}$ for fresh smoke in TRACE A derived by Anderson et al. [1996a].
Utilization of this value for young smoke implies that the aerosol mass in evolving smoke plumes increases by roughly a factor of 1.8 during evolution over a period of 1 to 3 days.

From the regression analysis it appears that most of this residual mass in the source apportionment is from the secondary production of aerosol particle mass from gases emitted by biomass buming. Because of the relatively few data points, there is much uncertainty in these regressions. Although a $30-40 \%$ mass increase due to combustion-produced secondary particles, which is suggested by the source apportionment regression model, is reasonable. Furthermore, examination of Figure $6 \mathrm{~b}$ shows that at $\mathrm{CO}$ concentration below $200 \mathrm{ppbv}$ the background aerosol concentration is $<5$ $\mu \mathrm{g} \mathrm{m}^{-3}$, which is less than the biogenic and soil background derived from the regression analysis.

\section{Chemistry of the Regional Hazes and Particle Growth by Condensation}

In this section we consider possible mechanisms for the significant increase in the mass concentration of particles as they age into the regional hazes. A breakdown of the species responsible for the secondary biomass burning component is given in Table 8. In this analysis we used the emission data from Ferek et al. [this issue] and the biogenic and soil chemical compositions from Talbot et al. [1988] and Artaxo et al. [1994, this issue]. For reasons discussed in section 6.2, the background sulfate concentration we used in Cuiabá (aged), Porto Velho, and Marabá were twice those given by Talbot et al. The results presented in Table 8 suggest that smoke aerosols grow in mass by about 20 to $40 \%$ during aging. As discussed in section 3 , the parcels over Porto Velho and Cuiabá (aged) contain smoke collected over a 1 to 4 day fetch. Therefore there was ample time for photochemical reactions. Furthermore, because of the high degree of convective activity in the Amazon Basin, the smoke was likely processed several times by clouds. This is no doubt the reason why the smoke sampled in Cuiabá (aged) and Porto Velho exhibited the greatest particle mass growth.

Table 8. Receptor Model Percentage Apportionment of Secondary Aerosol for Regional Hazes in Brazil

\begin{tabular}{|c|c|c|c|c|c|}
\hline & $\begin{array}{c}\text { Cuiabá } \\
\text { (Local) }\end{array}$ & $\begin{array}{l}\text { Cuiabá } \\
\text { (Aged) }\end{array}$ & $\begin{array}{l}\text { Porto } \\
\text { Velho }\end{array}$ & Marabá & $\begin{array}{c}\text { Potential } \\
\text { Mass } \\
\text { Increase }\end{array}$ \\
\hline \multicolumn{6}{|c|}{ Secondary products } \\
\hline $\mathrm{NH}_{4}^{+}$ & $0.6 \pm 0.3$ & $2.1 \pm 0.9$ & $2.4 \pm 1.0$ & $1.6 \pm 0.8$ & $6 \pm 1$ \\
\hline $\mathrm{C}_{2} \mathrm{O}_{4}^{=}$ & $1.1 \pm 0.7$ & $1.5 \pm 0.4$ & $2.3 \pm 1.0$ & $1.2 \pm 0.7$ & $24 \pm 6$ \\
\hline $\mathrm{SO}_{4}^{\prime=}$ & $0.4 \pm 1.0$ & $3.0 \pm 0.3$ & $6.8 \pm 0.9$ & $4.6 \pm 0.5$ & $8 \pm 2$ \\
\hline $\mathrm{NO}_{3}^{-}$ & $1.6 \pm 0.8$ & $2.1 \pm 0.9$ & $1.1 \pm 0.5$ & $1.6 \pm 0.5$ & $24 \pm 5$ \\
\hline Subtotals & $3.7 \pm 1.5$ & $8.7 \pm 1.4$ & $12.6 \pm 1.7$ & $9.0 \pm 1.3$ & $62 \pm 8$ \\
\hline Residue & $19 \pm 6$ & $31.3 \pm 8$ & $22.4 \pm 4$ & $8 \pm 6$ & $?$ \\
\hline Totals & $23 \pm 6.2$ & $40 \pm 8.1$ & $35 \pm 4.3$ & $17.0 \pm 6.1$ & \\
\hline
\end{tabular}

Data is presented as a percentage increase of aerosol mass contributed by each species (e.g., a value for $\mathrm{SO}_{4}^{=}$of 3.0 indicates that the aerosol mass was increased by $3 \%$ due to $\mathrm{SO}_{4}^{=}$). The sulfate apportionment assumes a background sulfate concentration of $2 \mu \mathrm{g}$ $\mathrm{m}^{-3}$. The residue is the measured increase in particle mass with age that cannot be accounted for by the measured species. Also included is the potential mass increase discussed in the text. 
Column 6 of Table 8 indicates the potential for vapor-phase emissions from forest fires to increase the mass of the aerosol as the smoke evolves. For ammonium this potential is computed assuming that $100 \%$ of the ammonia emitted from forest fires is converted to particulate ammonium. Because ammonia emission factors were not measured in SCAR-B, we used the emission factor given by $\mathrm{Hegg}$ et al. [1988] for biomass buming in southern California $\left(0.1 \mathrm{~g} \mathrm{NH}_{3}\right.$ per $\mathrm{kg}$ carbon burned). The potential of organic acids to increase particle mass was calculated assuming that all of the carbon in the hydrocarbons that was removed during the evolution of the smoke (33\% of C in NMHC) was converted to particulate matter. This value was multiplied by 1.3 to account for any additional oxygen and hydrogen in the molecules [Ferek et al., this issue]. The $\mathrm{NO}_{3}^{-}$potential was computed using the $\mathrm{NO}_{x}$ emission factor given by Ferek et al. and assuming a $100 \%$ nitrogen yield. The sulfate potential was computed similarly, assuming a $100 \%$ sulfur yield from $\mathrm{SO}_{2}$. We will now consider the role that each of these secondary species might play in the chemistry of the smoke-dominated regional hazes.

\subsection{Ammonium and Organic Chemistry}

Ammonium plus oxalate increased the aerosol mass by $-2-5 \%$ during the evolution of smoke from its source to regional haze. Because these species have low background concentrations relative to those in smoke and they correlate well with $\mathrm{CO}\left(r^{2}>0.70\right)$, they are likely associated with biomass burning. Ferek et al. [this issue] showed that there was very little particulate ammonium and oxalate in fresh smoke. The slope of the regression between ammonium to $\mathrm{CO}$
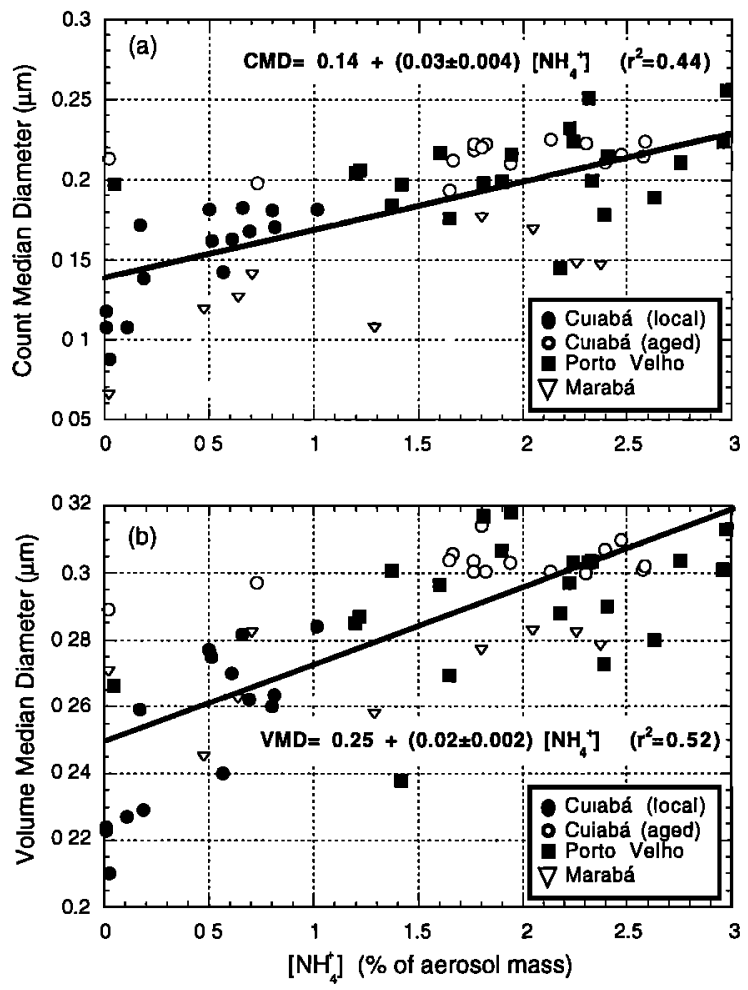

Figure 7. (a) Particle count median diameter (CMD) and (b) particle volume median diameters $(V M D)$ versus percentage of ammonium in the aerosol for regional hazes dominated by smoke in Brazil.

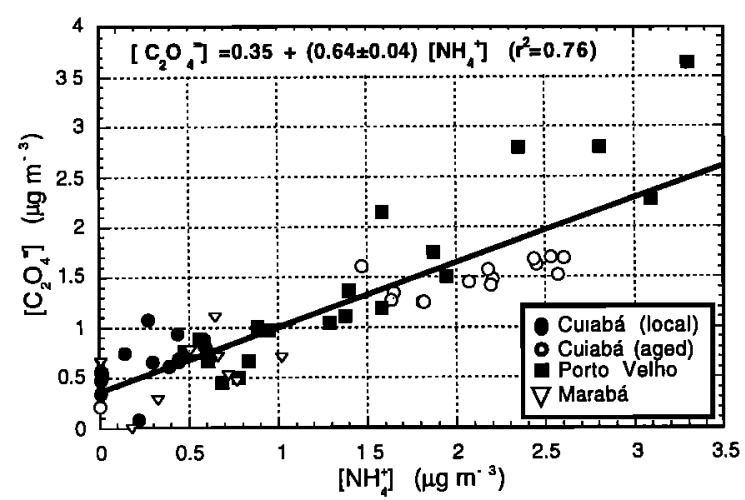

Figure 8. Concentration of oxalate $\left(\mathrm{C}_{2} \mathrm{O}_{4}\right)$ in the aerosol versus ammonium $\left(\mathrm{NH}_{4}^{+}\right.$concentration for regional hazes dominated by smoke in Brazil.

and ammonium to $\mathrm{CO}$ increases by over an order of magnitude during aging (from $<0.3 \mu \mathrm{g} \mathrm{ppm}^{-1}$ in fresh smoke to $4.0 \mu \mathrm{g}$ $\mathrm{ppm}^{-1}$ in the regional haze for both species). Therefore more than $95 \%$ of the particulate ammonium and oxalate found in the regional haze must have derived from secondary processes.

A mass increase of $5 \%$ would increase the volume median diameter of the smoke particles by $\sim 0.005 \mu \mathrm{m}$, compared to the measured increase of about $0.05 \mu \mathrm{m}$. Therefore ammonium and oxalate alone could not have had a significant effect on particle size. However, ammonium may be a key indicator of other growth processes. As shown in Figure 7, the ammonium concentration as a percentage of aerosol mass correlates reasonably well with the particle count and volume median diameters ( $r^{2}$ values of 0.44 and 0.52 , respectively). This correlation holds for the data collected at each location. The correlation of ammonium to the particle size parameters is significantly stronger than for any of the other species. The correlations of oxalate with the particle size parameters $C M D$ and $V M D$ are $r^{2}=0.23$ and 0.28 , respectively; sulfate and nitrate show no significant correlation with particle size parameters.

The fact that ammonium correlates with particle growth is important because ammonium concentrations measured on the filters provide a measure of ammonium in the air and the amount of ammonium required to bring the aerosol to a neutral $p \mathrm{H}$. Also, during sample extraction prior to IC analysis, amines, amides, and possibly nitriles can be hydrolyzed to ammonium and organic acids [Finlayson-Pitts and Pitts, 1986]. Therefore our ammonium measurements may include a portion of the soluble organic nitrogen species.

While no measurements of gas-phase ammonia were made in SCAR-B, biomass buming can produce large quantities of ammonia [Hegg et al., 1988]. If the ammonia emission factors in SCAR-B were similar to those measured by Hegg et al. in southern California, less than half of the ammonia emitted was converted to ammonium. With such an excess of ammonia available, most acidic species would likely be neutralized.

Ammonium correlated poorly with sulfate $\left(r^{2}=0.16\right)$, and it did not correlate with nitrate. Therefore we cannot determine how ammonium was associated with these species. However, oxalate and ammonium are highly correlated $\left(r^{2}=0.76\right.$; see Figure 8). The molar ratio of ammonium to oxalate from the regression is roughly 10:1. Since oxalate is a dicarboxilic acid, it requires two ammonium ions per molecule to be neutralized. Therefore $80 \%$ of the ammonium ion is 
unaccounted for. Because of the strong regression between ammonium and oxalate, and since oxalic acid is the predominant organic acid in evolving smoke [Andreae et al., 1988], it is likely that the ammonium was mostly associated with molecules that have similar chemical properties to oxalate, such as organic acids or amides (i.e., each unaccounted for ammonium molecule is associated with an acyl group, RCO, or a carboxylic group, RCOO). In this case, each ammonium molecule would have one carbonyl group (CO) associated with it. This implies that in Porto Velho, for example, the particle mass increased during evolution by at least another $3.3 \%$ due to these associated species. However, it is likely that each molecule is significantly longer than an ammonium molecule and a carbonyl group. For each additional carbon atom in the chain, the mass increase associated with ammonium rises by $1.3 \%$, and for each oxygen atom, the mass increase is $1.8 \%$. Therefore it is possible that a large fraction of the mass in the residue (i.e., the undetermined species) is associated with ammonium.

Organic acid vapor and particle production has been observed frequently in photochemical smog [Hartmann et al., 1989; Grosjean, 1990; Madronich et al., 1990 ; Satsumábayashi et al., 1990; Sakugawa and Kaplan, 1995] as well as in aging smoke plumes [Ardreae et al., 1988; Helas et al., 1992]. To date, the formation pathways are not well understood. Since ammonia is released in large quantities by biomass burning, much of the organic acid vapors released by fires, or photochemically produced in smoke plumes, is likely to be neutralized by ternary nucleation (in haze particle and cloud drops) or, possibly, even by gas-phase reactions.

If we were to assume that all of the particulate oxalic acid was generated from NMHC from fires, then there would be a 2\% carbon yield from the gas to the particulate phase. Because there are significantly more particulate organics present in the hazes than we measured, the carbon yield is likely to be significantly higher than this. However, Forstner et al. [1997] have shown that in a smog chamber, carbon yield from even the most reactive NMHC species is less than 5\%. On the basis of Forstner et al.'s data our conversion rates are unrealistically high. However, recent studies have shown that oxygenated hydrocarbons account for more than $40 \%$ of the NMHC emissions by biomass burning [Koppmann, 1997]. These species are so reactive that they usually do not survive long enough to be analyzed by sample methods such as we used in SCAR-B. We surmise that there is a very large reservoir of unquantified reactive hydrocarbon species released by biomass burning which play a role in rather rapid gas-to-particle conversion in the hazes.

Another possibility is that the observed rate of gas-to-particle conversion had a biogenic component that was accelerated by biomass burning. Gas-to-particle conversion reactions of biogenically produced gases may be rate limited by hydroxyl- and nitrogen-containing radicals [Hoffmann et al., 1997]. In the hazes we studied that $20-40 \%$ of the carbon in NMHC was associated with sources other than combustion (section 4). Furthermore, Hoffmann et al. have shown that some cyclic monoterpenes with biogenic sources can have extremely high gas-to-particle conversion rates with carbon yields from 5 to $40 \%$. Hence if biomass buming produces, both directly and indirectly, large quantities of the rate-limiting species, then the amount of photochemically produced biogenic particles could be increased significantly. Since the rate-limiting species are produced by biomass burning, this synergistic production of additional particle mass in the haze would be correlated with other species associated with biomass burning (such as $\mathrm{CO}, \mathrm{NH}_{4}^{+}, \mathrm{K}^{+}$, and BC).

\subsection{Sulfate Chemistry}

Sulfate is a significant component of the aerosol in the regional hazes (Table 6). In the Maraba and Porto Velho regions, sulfate comprised about $7 \%$ of the particle mass, compared to roughly $1-3 \%$ in young smoke [Ferek et al., this issue]. Sulfate is produced by sources other than biomass burning, including oxidation of biogenic and industrial emissions. Industrial emissions are minimal over the Amazon Basin, and recent modeling studies have shown little impact of anthropogenic emissions in this region [Liousse et al., 1997]. Biogenic emissions from the Amazon rain forest include a significant sulfur component [Andreae and Andreae, 1988; Andreae et al., 1990]. Biogenic emissions from the rain forest in the dry season include carbonyl sulfide (COS), dimethyl sulfide (DMS), hydrogen sulfide $\left(\mathrm{H}_{2} \mathrm{~S}\right)$, and $\mathrm{SO}_{2}$. These emissions result in boundary layer sulfate concentration in the Amazon Basin in the early dry season of $\sim 0.5-1 \mu \mathrm{g} \mathrm{m}^{-3}$ [Andreae and Andreae, 1988; Talbot et al., 1988]. In contrast, we found sulfate concentrations in the smoke-dominated hazes in Porto Velho and Marabá to be about $5 \mu \mathrm{g} \mathrm{m}^{-3}$ and, sometimes, as high as $10 \mu \mathrm{g} \mathrm{m}^{-3}$.

To investigate possible mechanisms for the high sulfate concentrations we measured in Porto Velho and Marabá, a regression of sulfate to $\mathrm{CO}$ was performed (Figure 9). Since there was little sulfate in the Cuiabá (local) regional hazes (probably because of the absence of cloud processing in the PBL), these data were removed from the analysis. The remaining sulfate data show a fair correlation with $\mathrm{CO}$ $\left(r^{2}=0.46\right)$, but they also indicate that there is a high background concentration of sulfate. If the regression line is extrapolated to a $\mathrm{CO}$ value typical of unpolluted continental air (100-200 ppbv), the sulfate concentration is found to be $\sim 1$ to $2 \mu \mathrm{g} \mathrm{m}^{-3}$. This is more than twice the value reported by Andreae and Andreae [1988] and Talbot et al. [1988] for the Amazon Basin.

At least two reasons can be suggested why our derived background sulfate concentration is higher than that measured by Andreae and Andreae [1988]. First, Andreae and Andreae noted that as the dry season progressed, the sulfate concentration increased due to sources other than biomass

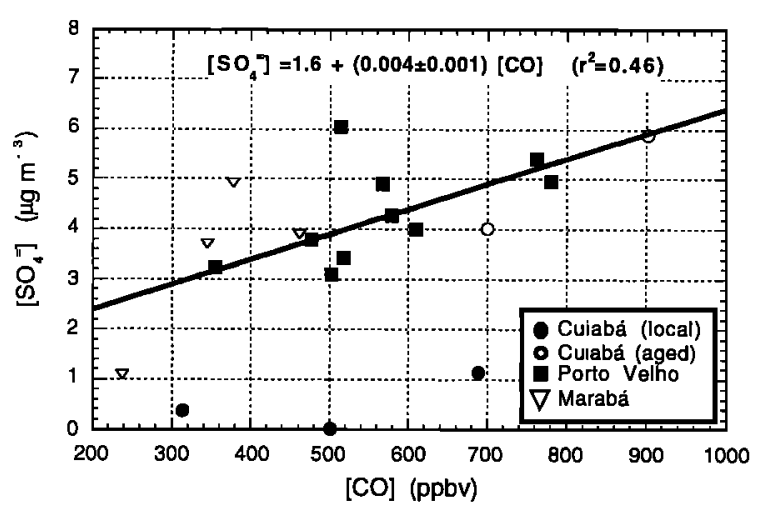

Figure 9. Concentration of sulfate $\left(\mathrm{SO}_{4}^{\overline{4}}\right)$ in the aerosol versus $\mathrm{CO}$ for regional hazes dominated by smoke in Brazil. 
burning. Their measurements stopped in early August, while our measurements in Porto Velho and Marabá were taken in September. Second, during our measurements in Porto Velho and Marabá, there was considerable convective activity. Thus the production of sulfate from biogenic gases may have been increased by heterogeneous reactions in clouds.

After accounting for the extra sulfate in Cuiabá (aged), Porto Velho, and Marabá, our CMB analysis (Table 8) indicates that combustion-generated aerosol increased in mass by $5-7 \%$ due to the addition of sulfate during aging. The source of this sulfate is likely the oxidation of sulfur-containing gases produced by biomass burning. For all of this sulfate to derive from gas-to-particle conversion of emitted $\mathrm{SO}_{2}$, there would need to be a $50-85 \%$ sulfate yield; this is somewhat higher than expected since $\mathrm{SO}_{2}$ has a large dry deposition velocity. Several possible explanations for these results are discussed below.

In the cloud-free regional hazes above Cuiabá (local), the sulfate component of the aerosol did not differ from that of young smoke (Table 6). When smoke was advected from the north over Cuiabá and when altocumulus clouds were present, there was a slight increase in the aerosol sulfate content. In Maraba the sulfate content of the aerosol was over $5 \%$, and the regional hazes were dominated by relatively young smoke that had been processed by large convective clouds (Table 6). In Porto Velho, well aged smoke that had been subjected to considerable cloud processing had an aerosol sulfate fraction $>7 \%$ (Table 6).

While these observations indicate the importance of cloud processing in the evolution of smoke particles, the required sulfate yield from heterogeneous $\mathrm{SO}_{2}$ oxidation alone is high. Samples of smoke exiting capping clouds over large fires (liquid water contents $>1 \mathrm{~g} \mathrm{~m}^{-3}$ ) showed very high sulfur oxidation rates, with sulfate yields $>60 \%$. Presumably, the average sulfate yield from clouds was less than this, although sulfate production rates of the order of several hundred percent per hour have been observed [Hegg and Hobbs, 1982]. It is also possible that $\mathrm{SO}_{2}$ oxidation is not the sole source of the sulfate found in the smoke aerosol [Andreae et al., 1997]. Other partially oxidized sulfur species such as COS and DMS are emitted from biomass burning and may evolve to sulfate.

Unlike organic acids, it is unclear what role ammonium plays in sulfur oxidation. Sulfate and ammonium concentrations are poorly correlated $\left(r^{2}=0.16\right)$, and sulfate has a much weaker correlation with the particle size parameters than ammonium. Furthermore, the molar ratio of ammonium to sulfate is relatively high. This is in stark contrast to the very high correlation between the molar fractions of ammonium and oxalate. This suggests that the form of sulfate in the regional hazes varies considerably among ammonium sulfate, ammonium bisulfate, and possibly other salts (e.g., $\mathrm{Na}_{2} \mathrm{SO}_{4}, \mathrm{CaSO}_{4}$, etc.).

\subsection{Soil and Nitrate Chemistry}

From the apportionment analysis in Table 6 it can be seen that soil particles made up roughly $10-20 \%$ of the particle mass with diameters $<\sim 4 \mu \mathrm{m}$. However, from the aerosol size distributions presented by Ross et al. [this issue], Anderson et al. [1996a] and Holben et al. [1996], it is evident that coarse particles $\left(2.5 \mu \mathrm{m}<d_{p}<15 \mu \mathrm{m}\right)$ can account for $30-60 \%$ of the total aerosol mass. When present in such high concentrations, coarse particles could have a large impact on an evolving fine-mode aerosol by serving as sites for heterogeneous reactions [Herring et al., 1996].

Scanning electron micrographs of aerosol samples taken in the regional hazes over Porto Velho and Maraba were used to apportion the sources of coarse particles. Coarse particles with diameters as large as $20 \mu \mathrm{m}$ were found on the filters, although they did not contribute significantly to the aerosol mass. Of the three hundred coarse particles analyzed, $89 \%$ were soils and clay minerals, $7 \%$ were combustion aggregates or ash, and $<4 \%$ were biogenic (plant matter, spores, etc.).

While soil particles may serve as reaction sites for gas-to-particle conversion, secondary aerosols that form on large soil particles will not influence the scattering or absorption of solar radiation. As discussed above, sulfate is not well correlated with particle size and may not be associated with the fine-mode aerosol. It is possible that much of the sulfate is a result of soluble iron-catalyzed $\left(\mathrm{Fe}^{3+}\right)$ heterogeneous chemistry in clouds. To test this hypothesis, soil particles collected in regions with considerable convection were analyzed by EDX to obtain qualitative information on their compositions. All of the particles analyzed were on filters with high total sulfate loadings. Of the 50 soil particles analyzed with iron strong $\mathrm{Fe}$ components, 42 had no trace of sulfur, five had a very weak sulfur signal, and three had a strong sulfur component. The three particles with very high sulfur concentrations probably had strong soil sulfur components. Recall that comparison of the IC and PIXE data suggests that only $80 \%$ of the sulfur in the aerosol is sulfate; the remaining $20 \%$ is likely in soil particles. The trace amounts of sulfur detected on five of the particles could have been due to sulfate nucleation in clouds. This analysis suggests that the majority of the sulfate that formed in the regional hazes was oxidized by in-cloud processes (other than iron-catalyzed reactions) by oxidants such as $\mathrm{H}_{2} \mathrm{O}_{2}$ and $\mathrm{O}_{3}$. Hence it is likely that the sulfate was present in the fine mode.

Nitrate is a more likely candidate for heterogeneous reactions on soils. Nitrate accounted for about $1.5 \%$ of the total aerosol mass in all three regions (Table 6). The aerosol particles increased their nitrate content by fourfold during the evolutionary process (Table 6). If all of this increase in nitrate is attributed to secondary production from the $\mathrm{NO}_{x}$ emitted by biomass burning, it would require a $4-8 \%$ nitrogen yield. It is evident that the nitrate content of the aerosols is not so dramatically influenced by plume history as sulfate and oxalate. Indeed, the correlations between nitrate and other secondary species, such as oxalate and ammonium, are extremely low $\left(r^{2}<0.15\right)$. However, nitrate was correlated with CO $\left(r^{2}=0.35\right)$, potassium $\left(r^{2}=0.30\right)$, and $\sigma_{a}\left(r^{2}=0.45\right)$, indicating a biomass burning component, and it was independently correlated with iron $\left(r^{2}=0.25\right)$, which suggest a soil component. While these correlations are low, they are at the $95 \%$ confidence level. The low correlations are likely due to the fact that nitrate is a difficult species to measure with collection methods due to artifacts. It should also be noted that the formation of ammonium nitrate from the neutralization of nitric acid by ammonia is a fast equilibrium reaction [Finlayson-Pitts and Pitts, 1986]. Ammonium nitrate can easily dissociate back into its reactants in both the aqueous and the solid phases. Hence it is difficult to say what role ammonium played in particulate nitrate formation.

Wolf [1984] postulated that the predominant mode of secondary nitrate production was through the reaction of 
gaseous nitric acid with soil dust. Talbot et al. [1988] reported that during the dry season in the Amazon Basin, $75 \%$ of the nitrate in the unpolluted mixed layer was associated with coarse-mode particles. Herring et al. [1996] showed that the $\mathrm{NO}_{x}$ oxidation rate in the smoke plume from the Kuwaiti oil fires was most strongly influenced by the amount of desert dust entrained into the plume.

If a large portion of the nitrate in the aerosol in the regional hazes in Brazil ends up on soil particles, it will not have a direct effect on the radiative properties of the aerosol. Also, if it contributes only $1.5 \%$ to the particle mass, it essentially has no effect on the coarse mode particle size distribution. However, since we collected only one half to one third of the soil particles in the hazes, there may be considerably more nitrate formation on them than we have estimated. Thus soil particles could be a significant sink for $\mathrm{NO}_{y}$ in smoke-dominated hazes in Brazil; if so, this has potentially important ramifications for photochemistry in the hazes.

\subsection{Residue}

The residue is the amount of aerosol particle mass that was unaccounted for by the species we measured (Table 6). The residue (assumed to be mainly organics) accounts for most of the mass of the aerosol.

The regression analysis showed that aerosol particles increased in mass by $10-30 \%$ due to species associated with the residue. Thus the residue accounts for roughly $25-75 \%$ of all secondary particle formation.

As discussed in section 5.3.1, part of the particle residue likely includes organic acids other than oxalate and amides. After accounting for these other acids, the increase in particle mass with age attributed to the residue was similar in all three locations $(-10$ to $20 \%)$. This implies that much of the increase in the residue is either associated with processes in the smoke plume that act on short timescales or it is due to contributions to the aerosol from other sources. The latter is unlikely because we made generous allowances for biogenic and anthropogenic emissions. Also, there is a strong correlation of the residue with $\mathrm{CO}\left(r^{2}=0.65\right)$, and the increase in residue is the same for both high and low aerosol concentrations.

Much of the residue was probably from the condensation of long chain hydrocarbons (carbon numbers $>11$ ) and PAHs within the first hours of emission. McKenzie et al. [1994] noted the presence of these species in combustion chamber experiments in which a clear organic liquid was extracted from laboratory-produced smoke. There is some field evidence to support this hypothesis. In a Lagrangian study of a biomass smoke plume in the Pacific Northwest of the United States, Hobbs et al. [1997] found that the particles almost doubled in volume over 2 hours of evolution. It was assumed that $85 \%$ of this mass gain was from water uptake. However, further analysis of this case suggests a different mass distribution. Kotchenruther and Hobbs [this issue] have shown that the humidification factor for smoke particles (in Brazil at least) is substantially lower than previously assumed. Consequently, much of the growth of the smoke particles previously attributed to water could have been due to the condensation of high volatility organic species.

The results of Babbitt et al. [1997] suggest considerable condensation of organics in smoke plumes. Particle emission factors derived from samples collected on towers in smoke from biomass burning in Brazil were less than half those derived from airborne samples obtained several hundred feet above the fires [Babbitt et al.,1997]. This suggests that condensation of high molecular weight hydrocarbons occurs rapidly following smoke emission. This is supported by the observations of Reid and Hobbs [this issue] that condensation is the dominant factor influencing the particle volume median diameters in fresh smoke. If a considerable amount of condensation occurs in the first few minutes of smoke emission, it is likely that it continues, albeit at reduced rates, for several hours.

The relationship between the $C M D$ and the $\sigma_{g c}$ also suggests a condensational growth mechanism. Recall that, $\sigma_{g c}$ is strongly anticorrelated with the particle median diameters. However, coagulation for particle size distributions of the type of interest here should not significantly change the geometric standard deviation $\left(\sigma_{g c}\right)$ of the distribution [Hinds, 1982]. Growth mechanisms consistent with this behavior are condensation-based processes [McMurry and Wilson, 1982].

\section{Particle Growth by Coagulation}

Our measurements in Brazil show that the CMD of the aerosol increased by at least $0.06 \mu \mathrm{m}$, and the $V M D$ increased by $0.05-0.09 \mu \mathrm{m}$, during the transformation over several days of young smoke into regional hazes. In this section we consider in more detail the contribution of coagulation to this growth.

In several previous studies it has been assumed that coagulation is the dominant mechanism responsible for particle growth in smoke plumes [Westphal and Toon, 1991; Liousse et al., 1995; Radke et al., 1995]. By performing a scale analysis, we can investigate the influence of coagulation on the size distribution of the smoke particles in Brazil. In this analysis we use the equation of Lee and Chen [1984] for the average coagulation coefficient of the aerosol

$$
\bar{K}=\frac{2 k T}{3 \eta}\left[1+e^{\ln ^{2} \sigma_{8 \varepsilon}}+\left(\frac{2.49 \lambda}{C M D}\right)\left(e^{0.5 \ln ^{2} \sigma_{8 c}}+e^{2.5 \ln ^{2} \sigma_{\delta^{s}}}\right)\right]
$$

where, $k$ is Boltzmann's constant, $T$ is temperature, $\eta$ is the gas viscosity, $\lambda$ is the molecular mean free path in the gas, $C M D$ is the count median diameter for the lognormal fit, and $\sigma_{g c}$ is the geometric standard deviation. The $C M D$ at times $t$ is given by

$$
(C M D)_{t}=(C M D)_{0}\left(1+N_{o} \bar{K} t\right)^{1 / 3}
$$

where $(C M D)_{o}$ is the $C M D$ at $t=0$, and $N_{o}$ is the initial particle number concentration.

In the individual smoke plumes we studied in SCAR-B, particle concentrations within $500 \mathrm{~m}$ of the fires were typically less than $150,000 \mathrm{~cm}^{-3}$. Using this value, and the $C M D$ and $\sigma_{g c}$ values for fresh smoke from Table $4(0.12 \mu \mathrm{m}$ and 1.73 , respectively), and assuming no dilution, we find that particles grow at a rate of $\sim 0.015 \mu \mathrm{m} \mathrm{h}^{-1}$. However, our measurements show that smoke plumes from fires in SCAR-B diluted by a factor of 2 in less than $5 \mathrm{~min}$ and by another factor of 2 in another $20 \mathrm{~min}$. With such dilution rates, $C M D$ would increase by less than $0.01 \mu \mathrm{m}$ within the first half hour of emission. Using a dilution half-life of $45 \mathrm{~min}$ beyond this time, the net particle growth is found to be $0.015 \mu \mathrm{m}$ in the 
2 hours required for a plume to be mixed to an ambient particle concentration of $10,000 \mathrm{~cm}^{-3}$.

The largest particle concentration observed in a smoke plume in SCAR-B was $600,000 \mathrm{~cm}^{-3}$, which would produce a very high coagulation rate. However, the majority of plumes sampled had particle concentrations below $100,000 \mathrm{~cm}^{-3}$ near their sources. Furthermore, on each flight, tens to hundreds of very small fires and plumes were observed, for which particle coagulation rates would have been very low. This scale analysis suggests that coagulation in fresh smoke plumes is not a major mechanism for particle growth in Brazil. This conclusion is supported by the results shown in Table 4, which show that for young smoke (Marabá and Cuiabá (local)) the $C M D$ is not much different from that of smoke a few minutes old.

The highest particle concentration observed in any regional haze was $10,000 \mathrm{~cm}^{-3}$ in Porto Velho. Substituting this value into (2) and using an average geometric standard deviation of 1.6 and an initial $C M D$ between 0.12 and $0.18 \mu \mathrm{m}$, the growth rate is found to bis $0.03 \mu \mathrm{m}$ per day. For a more typical particle concentration of $5000 \mathrm{~cm}^{-3}$, the growth rate of the $C M D$ is $0.015 \mu \mathrm{m}$ per day. Since smoke in regions such as Porto Velho can be more than 2 days old, the $C M D$ can grow by as much as $0.06 \mu \mathrm{m}$. The calculations indicate that after a plume has dispersed into a regional haze, particle coagulation can be a significant mech ism for particle growth over time periods of a few days.

From the above analysis and our previous discussions of the particle chemistry, we see that the age of emitted particles dictates the primary mechanism responsible for their growth. In the very near field, with timescales of minutes to an hour, growth by condensation is likely to be dominant. In regional hazes, over periods of 1 to 4 days, particle coagulation and condensation probably contribute about equally to particle growth. After 3 days, most of the condensation and gas-to-particle conversion has likely taken place, in which case coagulation would be the only significant particle growth mechanism.

It has been suggested that fine particles coagulate onto coarse particles, which will significantly alter the fine-mode size distribution and hence reduce fine particle light scattering and absorption [Radke et al., 1995]. To test this hypothesis, all soil particles were examined for the presence of fine particles on their surfaces. Approximately $40 \%$ of the soils were clay minerals, with smooth surfaces; particles that had coagulated onto these surfaces were easily visible. Most soil particles had less than 15 fine particles on their visible surface, and many had none at all. If we assume that roughly 3 times this many particles were on the complete particle, then less than 50 fine particles would be removed by each coarse particle. Fine particles $\left(0.05<d_{p}<2.5\right)$ were typically present in concentrations between 2000 and $10000 \mathrm{~cm}^{-3}$ and coarse particles in concentrations of $\ll 0.2 \mathrm{~cm}^{-3}$. Thus coagulation of fine particles onto coarse particles would remove at most 50 fine particles, or about $1 \%$ of the fine-mode mass. This suggests that over a period of 1 to 3 days, coagulation onto coarse particles is not a significant sink for fine particles.

This conclusion is supported by a simple scale analysis using the integrocoagulation equation. The loss rate of particles of diameter $d_{1}$ to particles of diameter $d_{2}$ can be expressed as

$$
\frac{d n\left(d_{1}\right)}{d t}=-K\left(d_{1}, d_{2}\right) n\left(d_{1}\right) n\left(d_{2}\right)
$$

where $K$ is the coagulation constant, and $n\left(d_{1}\right)$ and $n\left(d_{2}\right)$ are the number concentration of particles with diameters $d_{1}$ and $d_{2}$. Let us consider the coagulation of a $0.05 \mu \mathrm{m}$ particle onto a $10 \mu \mathrm{m}$ soil particle. The $K$ value for these particles is $\sim 10^{-7}$ $\mathrm{cm}^{3} \mathrm{~s}^{-1}$ [Seinfeld, 1986]. In the regional hazes over Brazil the number of fine particles with diameters $<0.1 \mu \mathrm{m}$ was always below $2000 \mathrm{~cm}^{-3}$. The number particles with diameters between 2.5 and $15 \mu \mathrm{m}$ was $\ll 0.2 \mathrm{~cm}^{-3}$. From this analysis we conclude that the number of susceptible fine-mode particles that coagulate with soil particles is less than 4 (or $0.2 \%$ ) per day.

\section{Optical Properties of Smoke Particles}

A summary of our measurements of particle mass-scattering efficiency $\alpha_{s}$, backscatter ratio $\beta(1)$, mass absorption efficiency $\left(\alpha_{a}\right)$, and single-scattering albedo $\left(\omega_{o}\right)$ for the regional hazes is given in Table 9 . The values listed in Table 9 compare reasonably well with Mie theory [Ross et al., this issue; Reid and Hobbs, this issue].

The large variations in particle size and chemistry with plume age is evident in the optical properties of the aerosol. Overall, there is an increase in the particle mass-scattering efficiency and the single-scattering albedo with the age of the smoke. Conversely, there is a decrease with age in the Angstrom coefficient (for scattering), the backscatter ratio, and the mass absorption efficiency. A lower value of the Angstrom coefficient and $\beta(1)$ implies increases in the $C M D$ and $V M D$, which is consistent with the observed particle growth during smoke aging. The dependence of the mass-scattering efficiency on plume age (i.e., location of the measurements) is shown in Figure 10, where $\alpha_{s}$ is plotted as a function of $V M D$. As expected, $\alpha_{s}$ increases with increasing $V M D$. Mie theory predicts that for a lognormal particle distribution similar to those measured in Brazil, for a refractive index of $1.5-0.02 i$, and for a growth law similar to that in Figure $4 \mathrm{~b}$, the mass-scattering efficiency should increase by $\sim 0.25 \mathrm{~m}^{2} \mathrm{~g}^{-1}$ per $0.01 \mu \mathrm{m}$ of $V M D$ growth; this is in good agreement with the measurements shown in Figure 10.

The mean values of the optical properties listed in Table 9 are for all of the components of the regional hazes (i.e., smoke, biogenic emissions, soils, etc.). Of the optical properties measured, $\alpha_{s}$ is most susceptible to the influence of soils and other coarse-mode particles. As discussed earlier, soil particles accounted for about $10 \%$ of the aerosol mass, and the value of $\alpha_{s}$ for soil particles with diameters in the range of $2.5-10 \mu \mathrm{m}$ is typically 0.7 to over $1 \mathrm{~m}^{2} \mathrm{~g}^{-1}$ [IPCC, 1995; Ouimette and Flagan, 1982]. The influence of soils was subtracted from $\alpha_{s}$ on a sample-by-sample basis, assuming that the soil particles had an $\alpha_{s}$ value of $0.85 \pm 0.15 \mathrm{~m}^{2} \mathrm{~g}^{-1}$. After the estimated effects of soils were removed, the mass-scattering efficiency of the well-aged hazes over Cuiabá and Porto Velho increased by $10 \%$ (Table 9). Therefore the values of $\alpha_{s}$ for smoke particles at midvisible wavelengths are increased by as much as $30 \%$ during aging.

Particle growth by coagulation and condensation should significantly increase the amount of light scattered in an evolving smoke plume. Both of these mechanisms will increase the $V M D$ and thus the mass-scattering efficiency of 
Table 9. Aerosol Particle Optical Parameters (Mean \pm Standard Deviation) for Cuiabá (Local Haze), Cuiabá (Aged Haze), Porto Velho, and Marabá

\begin{tabular}{|c|c|c|c|c|c|}
\hline Parameter & $\begin{array}{l}\text { Young } \\
\text { Smoke }\end{array}$ & $\begin{array}{l}\text { Cuiabá } \\
\text { (Local) }\end{array}$ & $\begin{array}{l}\text { Cuiabá } \\
\text { (Aged) }\end{array}$ & Porto Velho & Marabá \\
\hline $\begin{array}{l}\text { Angstrom coefficient } \\
\text { (for } \lambda=450-550 \mathrm{~nm} \text { ) }\end{array}$ & $2.2 \pm 0.2$ & $1.75 \pm 0.2$ & $1.2 \pm 0.2$ & $1.35 \pm 0.15$ & $1.45 \pm 0.2$ \\
\hline $\begin{array}{l}\text { Angstrom coefficient } \\
\text { (for } \lambda=550-700 \mathrm{~nm} \text { ) }\end{array}$ & $2.5 \pm 0.1$ & $2.6 \pm 0.1$ & $2.3 \pm 0.1$ & $2.3 \pm 0.10$ & $2.2 \pm 0.2$ \\
\hline $\begin{array}{l}\alpha_{s}\left(\text { in } \mathrm{m}^{2} \mathrm{~g}^{-1} \text { at } \lambda=450 \mathrm{~nm}\right) \\
\alpha_{s}\left(\text { in } \mathrm{m}^{2} \mathrm{~g}^{-1} \text { at } \lambda=550 \mathrm{~nm}\right) \\
\alpha_{s}\left(\text { in } \mathrm{m}^{2} \mathrm{~g}^{-1} \text { at } \lambda=700 \mathrm{~nm}\right)\end{array}$ & $\begin{array}{l}5.0 \pm 0.5 \\
3.2 \pm 0.5 \\
1.75 \pm 0.3\end{array}$ & $\begin{array}{l}4.1 \pm 0.9 \\
2.9 \pm 0.7 \\
1.6 \pm 0.3\end{array}$ & $\begin{array}{l}4.8 \pm 1.0 \\
3.8 \pm 0.8 \\
2.2 \pm 0.5\end{array}$ & $\begin{array}{l}4.4 \pm 0.9 \\
3.5 \pm 0.7 \\
2.0 \pm 0.4\end{array}$ & $\begin{array}{l}3.8 \pm 0.7 \\
2.9 \pm 0.6 \\
1.7 \pm 0.4\end{array}$ \\
\hline $\begin{array}{l}\beta(1)(\text { at } \lambda=450 \mathrm{~nm}) \\
\beta(1)(\text { at } \lambda=550 \mathrm{~nm}) \\
\beta(1)(\text { at } \lambda=700 \mathrm{~nm})\end{array}$ & $\begin{array}{l}0.16 \pm 0.02 \\
0.18 \pm 0.01 \\
0.21 \pm 0.02\end{array}$ & $\begin{array}{l}0.13 \pm 0.02 \\
0.15 \pm 0.02 \\
0.19 \pm 0.03\end{array}$ & $\begin{array}{l}0.11 \pm 0.01 \\
0.12 \pm 0.01 \\
0.14 \pm 0.01\end{array}$ & $\begin{array}{l}0.10 \pm 0.01 \\
0.11 \pm 0.01 \\
0.14 \pm 0.01\end{array}$ & $\begin{array}{l}0.11 \pm 0.01 \\
0.13 \pm 0.01 \\
0.15 \pm 0.01\end{array}$ \\
\hline$\alpha_{a}\left(\right.$ in $\mathrm{m}^{2} \mathrm{~g}^{-1}$ at $\left.\lambda=550 \mathrm{~nm}\right)$ & $0.85 \pm 0.3$ & $0.89 \pm 0.44$ & $0.73 \pm 0.2$ & $0.62 \pm 0.15$ & $0.60 \pm 0.1$ \\
\hline$\omega_{o}($ at $\lambda=550 \mathrm{~nm})$ & $0.79 \pm 0.05$ & $0.79 \pm 0.04$ & $0.85 \pm 0.02$ & $0.86 \pm 0.05$ & $0.83 \pm 0.02$ \\
\hline $\begin{array}{l}\text { Soil concentration removed } \\
\alpha_{s}\left(\text { in } \mathrm{m}^{2} \mathrm{~g}^{-1} \text { at } \lambda=450 \mathrm{~nm}\right) \\
\alpha_{s}\left(\text { in } \mathrm{m}^{2} \mathrm{~g}^{-1} \text { at } \lambda=550 \mathrm{~nm}\right) \\
\alpha_{s}\left(\text { in } \mathrm{m}^{2} \mathrm{~g}^{-1} \text { at } \lambda=700 \mathrm{~nm}\right)\end{array}$ & $\begin{array}{l}\text { na } \\
\text { na } \\
\text { na }\end{array}$ & $\begin{array}{l}4.5 \pm 1.2 \\
3.1 \pm 0.9 \\
1.7 \pm 0.4\end{array}$ & $\begin{array}{l}5.2 \pm 1.5 \\
4.1 \pm 0.9 \\
2.4 \pm 0.6\end{array}$ & $\begin{array}{l}4.9 \pm 1.3 \\
3.9 \pm 0.9 \\
2.2 \pm 0.5\end{array}$ & $\begin{array}{l}4.2 \pm 1.0 \\
3.2 \pm 0.9 \\
1.8 \pm 0.5\end{array}$ \\
\hline
\end{tabular}

Also shown are average values for young smoke from biomass buming from Reid and Hobbs [this issue] assuming an MCE of 0.89 . $\alpha_{s}$ is the mass-scattering efficiency, $\beta(1)$ is the backscatter ratio, $\alpha_{a}$ is the mass absorption efficiency, and $\omega_{0}$ is the single-scattering albedo.

the aerosol; condensation also decreases the geometric standard deviation of the particle distribution, which further increases the particle mass-scattering efficiency. The impact of these growth mechanisms on light scattering can be demonstrated by comparing the regression of light scattering to $\mathrm{CO}$ for young and aged smokes (Figure 11). In Figure 11 we see that the ratio of light scattering to $\mathrm{CO}$ increases from 0.33 to $0.51 \mathrm{~km}^{-1} \mathrm{ppmv}^{-1}(55 \%)$ during aging. If coagulation alone acted on the particles, the ratio of light scattering to $\mathrm{CO}$ should increase with age, as does the mass-scattering efficiency (from 3.2 to $4.1 \mathrm{~m}^{2} \mathrm{~g}^{-1}$ or $30 \%$; see Table 9). The most extreme data point for the young smoke regression $(\mathrm{CO}=17 \mathrm{ppmv})$ was produced by the atypical fire discussed above in connection with Figure 6. If this data point is removed from the regression, the slope of the regression for

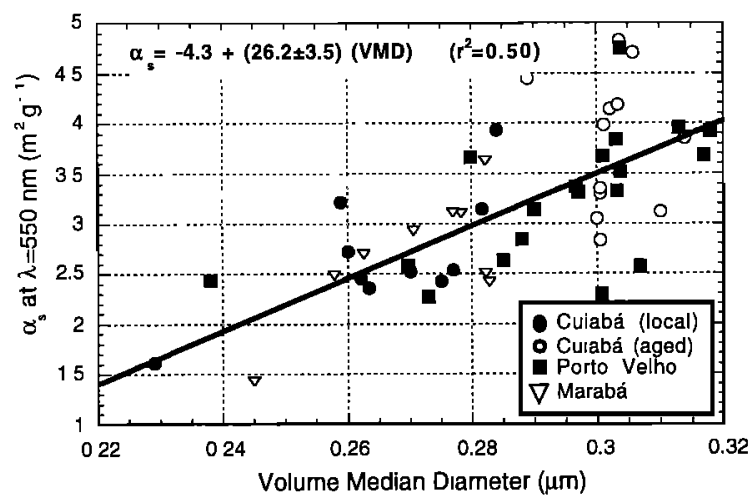

Figure 10. Aerosol mass scattering efficiency $\left(\alpha_{s}\right)$ at a wavelength of $550 \mathrm{~nm}$ versus the particle volume median diameter $(V M D)$ for regional hazes dominated by smoke in Brazil. young smoke decreases to $2 \mathrm{~km}^{-1} \mathrm{ppmv}^{-1}$. This implies that the ratio of light scattering to $\mathrm{CO}$ increases by more than a factor of 2.5! Although this is an extreme example, it demonstrates the uncertainty associated with estimates of the
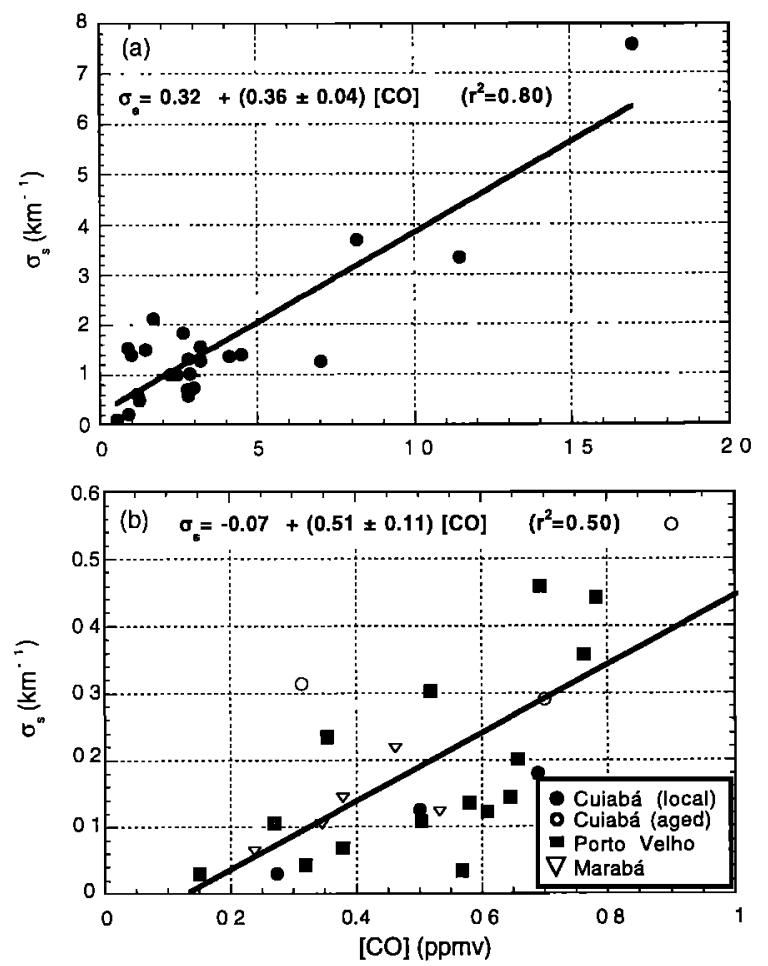

Figure 11. Aerosol light scattering ( $\sigma_{s}$ in inverse kilometers corrected to STP) versus CO for (a) young smoke from Ferek et al. [this issue] and (b) regional hazes dominated by smoke in Brazil. 
amount of light scattered per gram of particles produced by biomass burning.

The fine-mode backscatter ratio $\beta(1)$ was strongly anticorrelated with particle size. At a wavelength of $550 \mathrm{~nm}$, $\beta(1)$ is equal to 0.5 for particles of $0.01 \mu \mathrm{m}$ diameter and falls to 0.1 for particles $0.30 \mu \mathrm{m}$ diameter. Therefore as particles age and grow, the backscatter ratio should fall sharply. This is seen in Table 9, where $\beta(1)$ is equal to 0.18 for young smoke ("source") and falls to 0.10 in the well-aged hazes over Cuiabá and Porto Velho. Mie calculations suggest that the presence of soils and other coarse-mode aerosols did not have a dramatic effect on the derived values of $\beta(1)$.

The measured absorption properties of the aerosol are consistent with particle growth with age. Mie theory predicts that as particles grow by coagulation (i.e., no net mass growth), the mass absorption efficiency will decrease, and consequently, the single-scattering albedo will increase. If, as our data suggests, there is considerable condensation of organic species, this would further increase $\omega_{0}$. As seen in Table 9, there is a tendency for $\omega_{o}$ to increase with age. Reid and Hobbs [this issue] reported that for the fresh smoke plumes, $\omega_{o}$ ranged from 0.35 to 0.9 , with a mean value of 0.75 for flaming combustion and $\mathbf{0 . 8 2}$ for smoldering combustion. In comparison, for aged smoke over Cuiabá and Porto Velho the $\omega_{0}$ values ranged from 0.8 to 0.92 , with a mean of 0.86 . Thus the value of $\omega_{o}$ in the green wavelength increased by about 0.06 as the hazes aged over several days.

The aerosol backscatter ratio at a wavelength of $700 \mathrm{~nm}$ is significantly correlated with other particle properties $\left(r^{2}\right.$ values from 0.16 to 0.62 ); these correlations also hold at the blue and green wavelengths. This is important, since most Sun photometers have a red channel. Hence if the backscatter ratio in regional hazes dominated by smoke in Brazil is derived from Sun photometer measurements, reasonable estimates could be made of many of the physical and optical parameters of the particles. A listing of these regressions, valid for $\beta(1)$ values between 0.11 and 0.18 , is given in Table 10. For example, regressions of $V M D, \alpha_{s}$ (at $\lambda=550 \mathrm{~nm}$ ), and $\omega_{o}$ (at $\lambda=550 \mathrm{~nm}$ ) on to $\beta(1)$ are shown in Figures $12 \mathrm{a}, 12 \mathrm{~b}$, and $12 c$, respectively.

The correlation between the $V M D$ and the $\beta(1)$ is high $\left(r^{2}=0.8\right)$. This is due, in part, to a natural grouping of the data. The data points from the young smoke over Cuiabá, which had $\beta(1)$ values from 0.21 to 0.26 , strongly increase the

Table 10. Relations and Regression Coefficients $\left(r^{2}\right)$ for Some Key Particle Parameters to the Backscatter Ratio $\beta(1)$ at a Wavelength of $700 \mathrm{~nm}$

\begin{tabular}{ll}
\hline Regression Relation & $r^{2}$ \\
\hline$C M D=0.39-1.4 \beta(1)$ & 0.45 \\
$\sigma_{g c}=1.2-2.6 \beta(1)$ & 0.16 \\
$V M D=4.2-1.0 \beta(1)$ & 0.62 \\
$\sigma_{g v}=1.1-1.5 \beta(1)$ & 0.24 \\
$\alpha_{s}($ at $\lambda=450 \mathrm{~nm})=8.0-27 \beta(1)$ & 0.30 \\
$\alpha_{s}$ (at $\left.\lambda=550 \mathrm{~nm}\right)=6.9-27 \beta(1)$ & 0.30 \\
$\alpha_{s}($ at $\lambda=700 \mathrm{~nm})=4.3-18 \beta(1)$ & 0.37 \\
$\omega_{o}($ at $\lambda=550 \mathrm{~nm})=1.07-1.76 \beta(1)$ & 0.46 \\
\hline
\end{tabular}

These regressions are valid for $\beta(1)$ values between 0.1 and 0.18 . See text for definitions of symbols. All regressions except $\sigma_{g c}$ are significant at the $95 \%$ confidence level.
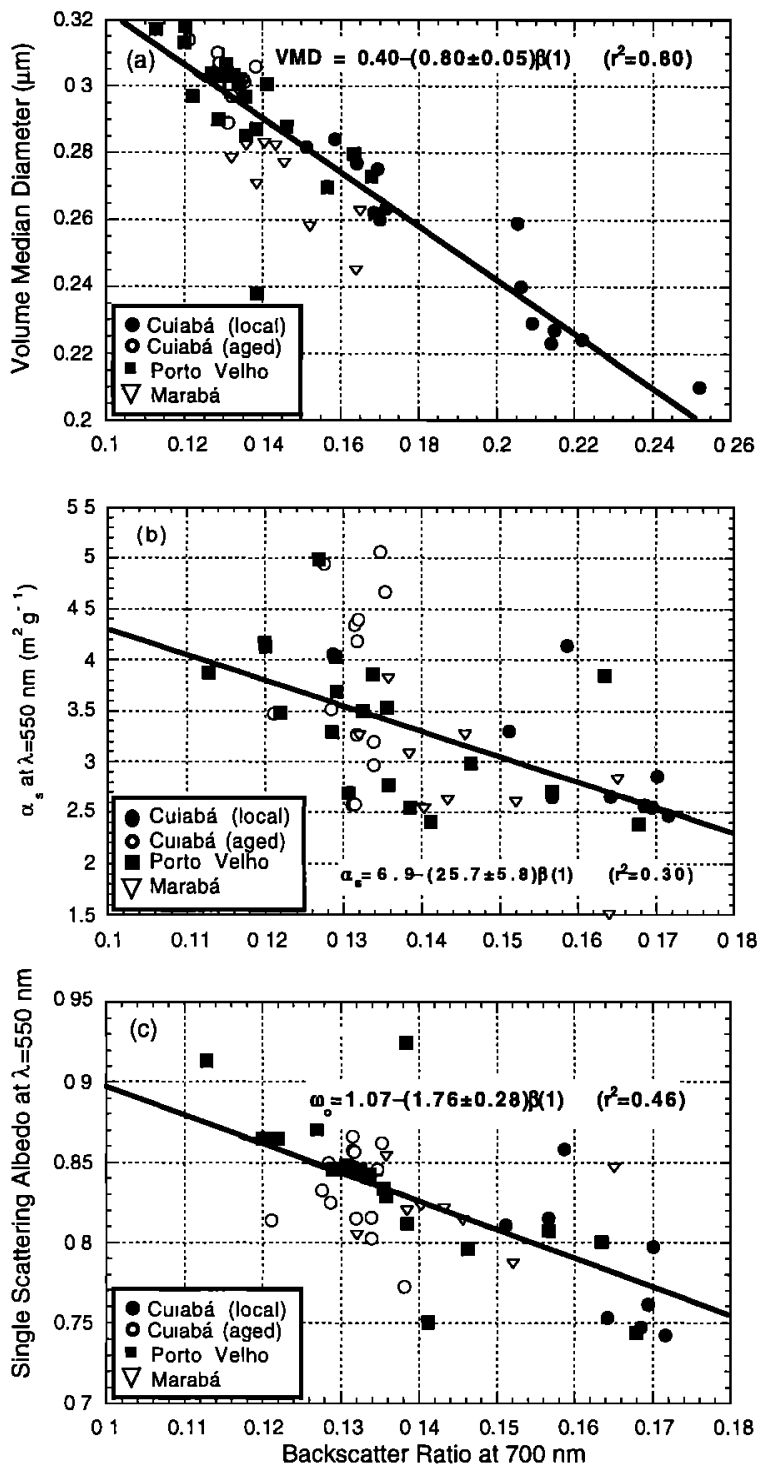

Figure 12. Particle volume median diameter (VMD) versus backscatter ratio at a wavelength of $700 \mathrm{~nm}$, (b) mass-scattering efficiency $\alpha_{s}$ at a wavelength of $550 \mathrm{~nm}$ versus particle backscattering ratio, and (c) single-scattering albedo at a wavelength of $550 \mathrm{~nm}$ versus the backscatter ratio at a wavelength of $700 \mathrm{~nm}$, for regional hazes dominated by smoke in Brazil.

correlation coefficient for the regression. However, the $\alpha_{s}$ and $\omega_{o}$ values for these data points are highly scattered. Therefore because of the natural grouping, these data points are not included in the regressions given in Table 10.

Correlations between $\alpha_{s}$ and $\omega_{o}$ with $\beta(1)$ are not so strong as that for the $V M D$. In the $\beta(1)$ interval $0.11-0.18$, the error in the regression slope is less than $20 \%$ and is significant at the $95 \%$ confidence level. Furthermore, data from all three locations are well scattered across the plot. Therefore if $\beta(1)$ at a wavelength of $700 \mathrm{~nm}$ can be estimated, some of the uncertainties in estimates of $\alpha_{s}$ and $\omega_{c}$ values can be reduced.

\section{Conclusions}

In this paper we have described measurements of the physical, chemical, and optical properties of regional hazes 
dominated by smoke from biomass burning in Brazil. The hazes were generally well mixed in the boundary layer and capped at an altitude of $\sim 3-4 \mathrm{~km}$ by the trade wind inversion. Particle concentrations were typically in the range 60-150 $\mathrm{\mu g}$ $\mathrm{m}^{-3}$, of which, on average, about $75 \%$ was from biomass burning, $15 \%$ from soils, and $10 \%$ from biogenic or other sources.

One of the principal findings of this paper is that the intrinsic properties of smoke, which has aged over several days, are quite different from those of young smoke. The ratio of NMHC to $\mathrm{CO}$ in the regional hazes were significantly lower than in young smoke. Most of the NMHC were likely reacted down to $\mathrm{CO}_{2}$ or $\mathrm{CO}$, or transformed into other species that we did not measure. The amount of carbon in the NMHC in the regional hazes was less by about $30 \%$ than in the young smoke. It is not known what fractions of this carbon were deposited on to aerosols and/or removed from the atmosphere.

Particles increased dramatically in size and mass with age. We have estimated that particle mass concentrations increased by about $20-45 \%$ over a period of 2 to 4 days and that about one half to three quarters of this mass increase was due to the condensation of organics. Over a period of 1 to 4 days, coagulation and condensation/gas-to-particle conversion probably contributed about equally to the increase in particle sizes. Over longer time periods, coagulation is probably the dominant growth mechanism.

Particle size was highly correlated with the ammonium content of the aerosol. Since ammonium was highly correlated with oxalate and poorly correlated with sulfate and nitrate, it is likely associated with the production of secondary organic species (such as carboxylic acids and amides). Since amides have a large molecular weight, they could contribute significantly to the increase in particle mass with age. The source of the gases responsible for this mass growth is unclear. It is likely that biomass buming produces large quantities of very reactive oxygenated compounds that were not detected in our NMHC analysis which could produce large gas-to-particle conversion rates. It is also possible that increases in hydroxyl and nitrogen-containing radicals in aging smoke plumes could enhance particle mass growth by the rapid gas-to-particle conversion of biogenic gases.

Sulfate concentrations in the aged smoke were high (average value $5 \mu \mathrm{g} \mathrm{m}^{-3}$ ) and contributed about $7 \%$ to the aerosol mass loading. In Porto Velho, sulfate was correlated with $\mathrm{CO}$; it is likely that most of this sulfate was a product of combustion. We estimate that $\sim 80 \%$ of the sulfate was a secondary product from sulfur emissions from biomass burning. Since sulfate concentrations were highest in regions with considerable convective activity, most of the secondary production of sulfate was probably due to cloud processing.

The large variability in particle size distributions induced equally large variations in the optical properties of the particles. The particle mass-scattering efficiency and single-scattering albedo increased with age. Conversely, the Angstrom coefficient for scattering, backscatter ratio, and mass absorption efficiency decreased with age. The backscatter ratio at a wavelength of $700 \mathrm{~nm}$ correlated particularly well with particle properties, such as size, absorption (at $\lambda=550 \mathrm{~nm}$ ), and scattering (at $\lambda=450,550$, and $700 \mathrm{~nm}$ ). Hence if the backscatter ratio in regional hazes dominated by smoke in Brazil is derived from Sun photometers, reasonable estimates could be made of many of the physical and optical parameters of the particles.
Acknowledgments. We thank University of Washington team members for their help in collecting data. In particular, we thank Dean Hegg for many helpful discussions. The University of Washington's participation in SCAR-B was supported by the following grants: NASA NAGW-3750 and NAG 11709; NSF ATM-9400760, ATM-9412082, and ATM-9408941; NOAA NA37RJ0198AM09 (JSAO contribution number 518); and EPA CR822077.

\section{References}

Anderson, B. E., W. B. Grant, G. L. Gregory, E. V. Browell, J. E. Collins Jr., D. W. Sachse, D. R. Bagwell, C. H. Hudgins, D. R. Blake, and N. J. Blake, Aerosols from biomass buming over the tropical South Atlantic region: Distributions and impacts, J. Geophys. Res., $101,24,117-24,137,1996$ a.

Anderson, T. L., et al., Performance characteristics of a high-sensitivity, three-wavelength, total scatter/backscatter nephelometer, J. Atmos. Oceanic Technol., 13, 967-986, 1996b.

Andreae, M. O., Biomass buming: Its history, use, and distribution and its impact on environmental quality and global climate, in Global Biomass Burning: Atmospheric, Climactic and Biospheric Implications, edited by J. S. Levine, pp. 3-21, MIT Press, Cambridge, Mass., 1991.

Andreae, M. O., and T. W. Andreae. The cycle of biogenic sulfur compounds over the Amazon Basin, 1, Dry season, J. Geophys. Res., 93, 1487-1497, 1988.

Andreae, M. O., et al., Biomass burning emissions and associated haze layers over Amazonia, J. Geophys. Res., 93, 1509-1527, 1988.

Andreae, M. O., H. Berresheim, H. Bingemer, D. J. Jacob, B. L. Lewis, S. M. Li, and R. W. Talbot, The atmospheric sulfur cycle over the Amazon Basin, J. Geophys. Res., 95, 16,813-16,824, 1990.

Andreae, M. O., E. Atlas, H. Cachier, W. R. Cofer III, G. W. Harriss, G. Helas, R. Koppmann, J. P. Lacaux, and D. E. Ward, Trace gas and aerosol emissions from savannah fires, in Biomass Burning and Global Change, edited by J. S. Levine, pp. 278-295, MIT Press, Cambridge, Mass., 1997.

Artaxo, P., F. Gerab, M. A. Yamasoe, and J. V. Martins, Fine mode aerosol composition at three long-term atmospheric monitoring sites in the Amazon Basin, J. Geophys. Res., 99, 22,857-22,868, 1994.

Artaxo, P., E. T. Fernades, J. V. Martins, M. A. Yamasoe, P. V. Hobbs, W. Maenhaut, K. M. Longo, and A. Castanho, Large-scale aerosol source apportionment in Amazonia, J. Geophys. Res., this issue.

Babbitt, R. E., D. E. Ward, R. S. Susout, P. Artaxo, and J. B. Kaufman, A comparison of concurrent airborne and ground-based emissions generated from biomass burning in the Amazon Basin, in SCAR-B Proceedings, edited by V. Kirchhoff ed,, pp. 23-26, Transtec. Ed., Sao José dos Campos, Brazil, 1997.

Blake, N. J., D. R. Blake, B. C. Sive, T. Chen, F. S. Rowland, J. E. Collins Jr., G. W. Sachse, and B. E. Anderson, Biomass buming emissions and vertical distribution of atmospheric methyl halides and other reduced carbon gases in the South Atlantic region, J. Geophys. Res., 101, 24,151-24,164, 1996.

Cachier, H., M. P. Brémond, and P. Buat-Ménard, Determination of atmospheric soot carbon with a simple thermal method, Tellus, Ser. B, 41, 379-390, 1989.

Christopher, S. A., D. V. Kliche, J. Chou, and R. M. Welch, First estimates of the radiative forcing of aerosols generated from biomass buming using satellite data, J. Geophys. Res., 101, 21,265-21,273, 1996.

Ferek, R. J., J. S. Reid, P. V. Hobbs, D. R. Blake, and C. Liousse, Emission factors of hydrocarbons, halocarbons, trace gases, and particles from biomass buming in Brazil, J. Geophys. Res., this issue.

Finlayson-Pitts, B. J., and J. N. Pitts, Atmospheric Chemistry: Fundamentals and Experimental Techniques, John Wiley, New York, 1986.

Forstner, J. L., R. C. Flagan, and J. H. Seinfeld, Secondary organic aerosol from the photooxidation of aeromatic hydrocarbons: Molecular composition, Environ. Sci. Technol., 31, 1345-1358, 1997.

Grosjean, D., Formic acid and acetic acid measurements during the southem California air quality study, Atmos. Environ., 24A, 2699-2702, 1990.

Hartmann, W. R., M. O. Andreae, and G. Helas, Measurements of organic acids over central Germany, Atmos. Environ, 23, 1531-1533, 1989.

Hegg, D. A., and P. V. Hobbs, Measurements of sulfate production in natural clouds, Atmos. Environ., 16, 2663-2668, 1982. 
Hegg, D. A., L. F. Radke, and P. V. Hobbs, Ammonia emissions from biomass burning, Geophys. Res. Lett., 15, 335-337, 1988.

Hegg, D. A., D. S. Covert, M. J. Rood, and P. V. Hobbs, Measurements of aerosol optical properties in marine air, J. Geophys. Res., 101, 12,893-12,903, 1996.

Helas, G., H. Bingemer, and $O$. Andreae, Organic acids over equatorial Africa: Results from DECAFE 88, J. Geophys. Res., 97, 6187-6193, 1992.

Herring, J. A., R. J. Ferek, and P. V. Hobbs, Heterogeneous chemistry in the smoke plumes from the 1991 Kuwait oil fires, J. Geophys. Res., $101,14,451-14,463,1996$.

Hinds, W. C, Aerosol Technology: Properties, Behavior, and Measurement of Airborne Particles, Wiley-Interscience, New York, 1982.

Hobbs, P. V., Summary of types of data collected on the University of Washington's Convair C-131A aircraft in the Smoke, Clouds and Radiation-Brazil (SCAR-B) field study from 17 August-20 September 1995, 1996. (Available on the worldwide web at http://cargsun2,atmos.washington.edu)

Hobbs, P. V., J. S. Reid, J. A. Herring, J. D. Nance, R. E. Weiss, J. L. Ross, D. A. Hegg, R. D. Oumar, and C. A. Liousse, Particle and trace-gas measurements in the smoke from prescribed bums of forest products in the Pacific Northwest, in Biomass Burning and Global Change, edited by J. S. Levine, Pp. 697-715, MIT Press, Cambridge, Mass., 1997.

Hoffmann, T., J. R. Odum, F. Bowman, D. Collins, D. Klockow, R. C. Flagan, and J. H. Seinfeld, Formation of organic aerosols from the oxidation of biogenic hydrocarbons, J. Atmos. Chem., 26, 189-222, 1997.

Holben, B. N., A. Setzer, T. F. Eck, A. Pereira, and I. Slutsker, Effect of dry-season biomass burning on the Amazon Basin aerosol concentrations and optical properties, 1992-1994, J. Geophys. Res., $101,19,7465-19,481,1996$.

Hopke, P. K., Receptor Modeling in Environmental Chemistry, John Wiley, New York, 1985.

Intergovernmental Panel on Climate Change (IPCC), Climate Change 1994: Radiative Forcing of Climate Change, edited by J. T. Houghton et al., Cambridge Univ. Press, New York, 1995.

Kaufman, Y. J., et al., Smoke, Clouds and Radiation Brazil (SCAR-B) experiment, J. Geophys. Res., this issue.

Koppmann, R., Emissions of volatile organic compounds from biomass buming, paper presented at the Workshop on Volatile Organic Compounds in the Troposphere, German American Academic Council, Julich, Germany, Oct. 27-31, 1997.

Kotchenruther, R., and P. V. Hobbs, Humidification factors of aerosols from biomass buming in Brazil, J. Geophys. Res., this issue.

Larson, T. V., and J. Q. Koenig, Wood smoke: Emissions and noncancer respiratory effects, Ann. Rev. Public Heallh, 15, 133-156, 1994.

Lee, L. W., and C. Chen, Coagulation rate of polydisperse particles, Aerosol Sci. Technol., 3, 327-334, 1984.

Liousse, C., C. Devaux, F. Dulac, and H. Cachier, Aging of savannah biomass buming aerosols: Consequences on their optical properties, J. Almos. Chem., 22, 1-17, 1995.

Liousse, C., H. Cachier, and W. Guelle, Modeling tropical biomass buming: Determination of a global climatology for Southem America, Eos Trans. AGU, 78(17), Spring Meet. Suppl., S78, 1997.

Madronich, S., R. B. Chatfield, J. G. Calvert, G. K. Moortgat, B. Veyret, and $R$. Lesclaux, A photochemical origin of acetic acid in the troposphere, Geophy. Res. Lett., 17, 2361-2364, 1990.

McKenzie, L. M., W. M. Hao, G. N. Richards, and D. E. Ward, Quantification of major components emitted from smoldering combustion of woods, Atmos. Environ., 28, 3285-3292, 1994.

McKenzie, L. M., D. W. Ward, and W. M. Hao, Chlorine and bromine in the biomass of tropical and temperate ecosystems, in Biomass Burning and Global Change, edited by J. S. Levine, pp. 241-248, MIT Press, Cambridge, Mass., 1997.

McMurry, P. H., and J. C. Wilson, Growth laws for the formation of secondary ambient aerosols: Implications for chemical conversion mechanisms, Atmos. Environ., 16, 121-134, 1982.

Norusis, M. J., SPSS Professional Statistics 6.1, pp. 113-168, SPSS Inc., Chicago, III., 1994.

Ouimette, J. R., and R. C. Flagan, The extinction of muliticomponent aerosols, Atmos. Environ., 16, 2405-2419, 1982.

Pereira, E. B., A. W. Setzer, F. Gerab, P. E. Artaxo, M. C. Pereira, and G. Monroe, Airbome measurements of aerosols from biomass buming in Brazil related to the TRACE A experiment, J. Geophys. Res., 101, 23,983-23,992, 1996.
Pickering. K.E., et al., Convective transport of biomass buring emissions over Brazil during TRACE A, J. Geophys. Res., 101, 23,993-24,012, 1996.

Prins, E. M., W. P. Menzel, and D. W. Ward, GOES-8 ABBA diumal fire monitoring during SCAR-B, in SCAR-B Proceedings, edited by V. Kirchhoff, pp. 153-157. Transtec. Ed., Sao José dos Campos, Brazil, 1997.

Pueschel, R. F., V. R. Overbeck, K. G. Snetsinger, P. B. Russell, G. V. Ferry, J. C. Wilson, J. M. Livingston, S. Verma, and W. Fong, Calibration correction of an active scattering spectrometer probe to account for the refractive index of stratospheric aerosols, Aerosol Sci. Technol., 12, 992-1002, 1990.

Radke, L. F., D. A. Hegg, P. V. Hobbs, and J. E. Penner, Effects of aging on the smoke from a large forest fire, Atmos. Res., 38, 315$332,1995$.

Reid, J. S., and P. V. Hobbs, Physical and optical properties of young smoke from individual biomass fires in Brazil, J. Geophys. Res., this issue.

Reid, J. S., P. V. Hobbs, C. Liousse, J. V. Martins, R. E. Weiss, and T. F. Eck, Comparisons of techniques for measuring shortwave absorption and black carbon content of aerosols from biomass buming in Brazil, $J$. Geophys. Res., this issue.

Ross, J., P. V. Hobbs, and B. Holben, Radiative characteristics of regional hazes dominated by smoke from biomass buming in Brazil: Closure tests and direct radiative forcing, J. Geophys. Res., this issue.

Sakugawa, H., and I. R. Kaplan, Stable carbon isotope measurements of atmospheric organic acids in Los Angeles, Califomia, Geophys. Res. Lett., 22, 1509-1512, 1995.

Satsumbayashi, H., H. Kurita, Y. Yokouchi, and H. Ueda, Photochemical formation of particulate dicarboxilic acids under long-range transport in central Japan, Atmos. Environ., 24A, 1443$1450,1990$.

Sehmel, G. A., Particle and gas dry deposition: A review, Atmos. Environ., 14, 983-1011, 1980.

Seinfeld, J.H., Atmospheric Chemistry and Physics of Air Pollution, John Wiley, New York, 1986.

Talbot, R. W., M. O. Andreae, T. W. Andreae, and R. C. Harris, Regional aerosol chemistry of the Amazon Basin during the dry season, J. Geophys. Res., 93, 1499-1508, 1988.

Thurston, G. C., and J. D. Spengler, A quantitative assessment of source contributions to inhalable particulate matter pollution in metropolitan Boston, Atmos. Environ., 19, 9-25, 1985.

Ward, D. E., Factors influencing the emissions of gases and particulate matter from biomass buming, in Fire in the Tropical Biota, edited by J. G. Goldammer, pp. 418-436, Springer-Verlag, New York, 1990.

Westphal, D. L., and O. B. Toon, Simulations of microscale, radiative, and dynamical processes in a continental-scale forest fire smoke plume, J. Geophys. Res., 96, 22,379-22,400, 1991.

Winklmayr, W., G. P. Reischl, A. O. Lindner, and A. Berner, A new electromobility spectrometer for the measurement of the aerosol size distributions in the size ranges of 1 to $1,000 \mathrm{~nm}, J$. Aerosol Sci., 22, 289-296, 1991.

Wolf, G. T., On the nature of nitrate in coarse continental aerosols, Atmos. Environ., 18, 977-981, 1984.

Zimmerman, P. R., J. P, Greenberg, and C. E. Westburg, Measurements of atmospheric hydrocarbons and biogenic fluxes in the Amazon boundary layer, J. Geophys. Res., 93, 1407-1416, 1988.

D. R. Blake, Department of Chemistry, University of California, Irvine, CA 92697. (e-mail: dblake@orion.oac.uci.edu.)

M. R. Dunlap, Facility for Advanced Instrumentation, University of Califomia, Davis, CA 95616. (e-mail: mrdunlap@ucdavis.edu.)

R. J. Ferek, P. V. Hobbs (corresponding author), and J. S. Reid, Department of Atmospheric Sciences, University of Washington, Box 351640, Seatule,WA 98195-1640. (e-mail: ferekr@onr.navy.mil; phobbs@atmos.washington.edu; reid@atmos.washington.edu.)

C. Liousse, Centre des Faibles Radioactivités, Laboratoire Mixte CNRS-CEA, Gif-Sur-Yvette, France. (e-mail: cachier@eole.cfr. cnrs-fig.fr.)

J. V. Martins, Instituto de Física, Universidade de São Paulo, São Paulo, Brazil. (e-mail: vanderlei@if.usp.br.)

(Received September 9, 1997; revised February 2, 1998; accepted February 4, 1998.) 